\title{
Universal Host Materials for Red, Green and Blue High-Efficiency Single-Layer Phosphorescent Organic Light- Emitting Diodes
}

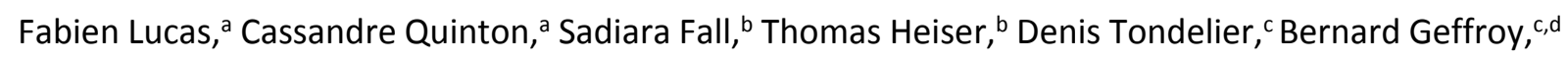
Nicolas Leclerc, ${ }^{\mathrm{e}}$ Joëlle Rault-Berthelot, ${ }^{a}$ and Cyril Poriel ${ }^{{ }^{*}}$

a Univ Rennes, CNRS, ISCR-UMR CNRS 6226, F-35000 Rennes, France- email: cyril.poriel@univrennes1.fr

${ }^{b}$ Laboratoire ICube, Université de Strasbourg, UMR CNRS 7357, 67087 Strasbourg, France

c LPICM, CNRS, Ecole Polytechnique, Institut Polytechnique de Paris, route de Saclay, 91128 Palaiseau, France

d Université Paris-Saclay, CEA, CNRS, NIMBE, LICSEN, 91191, Gif-sur-Yvette, France

e Institut de Chimie et Procédés pour l'Énergie, l'Environnement et la Santé (ICPEES), UMR CNRS 7515, 67087 Strasbourg, France

Keywords: Host materials, Single-layer red, green and blue phosphorescent organic light-emitting diode, Ambipolar charge transport, Spiro compounds, Phosphine oxide, Positional isomerism

TOC

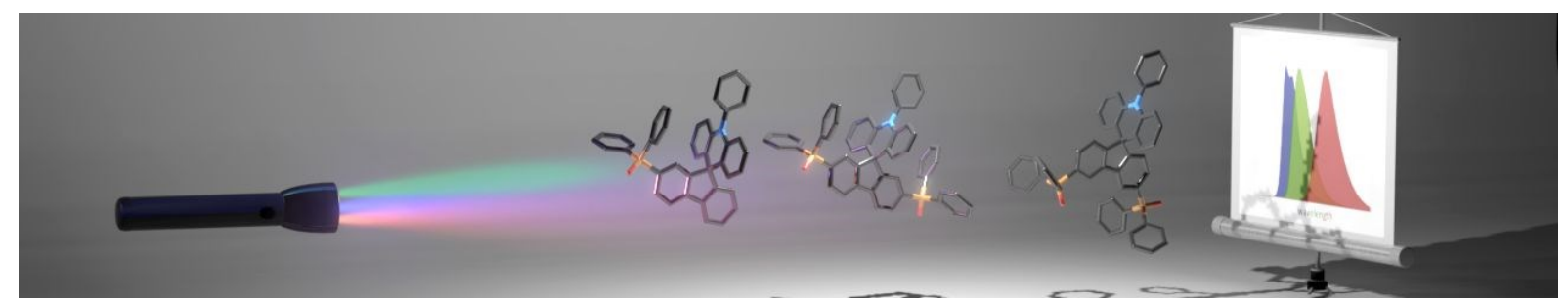

\section{Abstract}

Simplifying the structure of Organic Light-Emitting Diodes (OLEDs) has been for the last twenty years the purpose of many studies. However, despite these efforts, only a few materials provide high efficiency devices. We report herein efficient design strategies to construct universal host materials for red, green and blue Single-Layer Phosphorescent OLEDs (SL-PhOLEDs). The three materials investigated, SPA-2,7-F(POPh $\left.\left.{ }_{2}\right)_{2}, \mathbf{S P A - 3 , 6 - F ( P O P h}\right)_{2}$ and SPA-2-FPOPh ${ }_{2}$, have been synthesized via an efficient approach and are constructed on the association of an electron rich phenylacridine unit connected by a spiro carbon atom to three different electron-deficient diphenylphosphineoxidesubstituted fluorenes. Electrochemical, spectroscopic, thermal and transport properties are discussed. The position ( $\mathrm{C} 2$ and $\mathrm{C} 7$ vs. $\mathrm{C} 3$ and $\mathrm{C} 6$ ) and the number ( 1 vs. 2) of diphenylphosphineoxide units on the fluorene backbone have been particularly studied to highlight the best combination in term of device performances. Red, green and blue SL-PhOLEDs (RGB SL-PhOLEDs) have been fabricated and characterized and their performances discussed. Of particular interest, we managed to reach a Flr6based SL-PhOLED (with SPA-2-FPOPh ${ }_{2}$ ) possessing an external quantum efficiency of $9.1 \%$ and a low threshold voltage (below $3 \mathrm{~V}$ ). As far as we know, this is the first example of SL-PhOLED using this blue phosphorescent emitter. On the other hand, with notably a very high external quantum efficiency of $18 \%$ with Flrpic as sky blue emitter, SPA-2,7-F(POPh $)_{2}$ displays the highest overall performance in the series and among the highest overall performance ever reported for RGB SL-PhOLEDs using a universal host. This not only shows that the association of phenylacridine and diphenylphosphineoxide units fulfils the required criteria for an universal host for high efficiency SL-PhOLEDs but also highlights that the arrangement of these fragments drives the device performance. 
The development of efficient organic host matrices for the emissive layer (EML) of Phosphorescent Organic Light-Emitting Diodes (PhOLEDs) ${ }^{1}$ is at the origin of the fantastic progresses made by this technology in the last twenty years. ${ }^{1-4}$ The role played by the host matrix is crucial as it should prevent energy back transfers from the guest emitter to the host and favour the confinement of excitons. Today, the rational design of host materials for guest phosphors has allowed to reach very highefficiency red, green or blue PhOLEDs (with external quantum efficiency EQE $>25 \%$ ). ${ }^{5-18}$ However, all these are multi-layer devices, which are constituted of a stack of organic layers in order to improve the injection, transport and recombination of charges within the EML. To reduce the cost and the environmental footprint of the OLED technology, simplifying the multi-layer structure is one interesting direction for the future. ${ }^{19}$ The so-called Single-Layer PhOLEDs (SL-PhOLEDs), the simplest device only made of the electrodes and the EML, have thus stimulated a strong interest for the last fifteen years. However, reaching high efficiency SL-PhOLEDs of all the colours ( $r e d,{ }^{20-25}$ yellow, ${ }^{21,} 26,27$ orange, ${ }^{26,27}$ green, ${ }^{21,23,26,28-34}$ blue $^{23,24,33,35-37}$ and white ${ }^{38}$ ) is a difficult task as removing the functional organic layers of a PhOLED stack leads to a dramatic decrease of the performance. Simplifying the PhOLED technology goes also through the use of high-efficiency universal materials which can efficiently host red (R), green (G) and blue (B) phosphors.

Some examples have shown that, with rational designs, the host material can perform the job of the numerous functional organic layers used in multi-layer structures. Thus, an ideal host material for RGB SL-PhOLEDs should fulfil several criteria: (i) a high triplet state energy $E_{T}>2.7 \mathrm{eV}$ to confine the triplet excitons within phosphorescent guest, (ii) HOMO/LUMO energy levels well adapted to the electrode Fermi levels allowing efficient charge injection, (iii) good and well balanced mobilities of electrons and holes (ambipolar character) in order to compensate for the absence of electron/hole transporting layers, ${ }^{39}$ and (iv) thermal and morphological stabilities to extend the lifetime of the devices. These four criteria can be fulfilled by the careful association of an electron-rich and an electron-deficient unit within a single molecule. However, while some examples of very high performance RGB multi-layer PhOLEDs have been recently described, ${ }^{5}, 18,40-45$ RGB SL-PhOLEDs remain very rarely reported in literature. ${ }^{23,24}$

Thus, in the present work, we consider the simplest EML of a SL-PhOLED only constituted of one host material and the phosphor. The literature also reports other strategies to reach high efficiency SLPhOLEDs such as a host/co-host combination in the EML. Despite high EQE have been obtained, this strategy ${ }^{46-50}$ requires several molecules instead of only one in conventional SL-PhOLEDs. Other simplified devices architectures have also been used in the literature, with one or two undoped regions of the host material on each side of the EML. ${ }^{51,52}$

Recently, we have shown that phenylacridine/diphenylphosphine oxide association in SPA-2,7$\mathbf{F}\left(\mathbf{P O P h}_{2}\right)_{2}$ (See structure in Scheme 1 ) is very efficient to reach high performance green and blue SLPhOLEDs. ${ }^{33}$ In the present work, we report a structure properties relationship study involving three bipolar hosts (SPA-2,7-F(POPh $\left.)_{2}\right)^{33}$ SPA-3,6-F(POPh $)_{2}$ and SPA-2-FPOPh ${ }_{2}$ ) constructed on the association of the electron-rich phenylacridine and the electron-poor diphenylphosphine oxide. The position ( $\mathrm{C} 2$ and $\mathrm{C} 7$ vs $\mathrm{C} 3$ and $\mathrm{C} 6$ ) and the number (1 vs 2 ) of diphenylphosphineoxide units on the fluorene backbone have been studied in detail to highlight the best combination in term of device performances. Such study are the foundation of organic electronics to reach high performance devices. Finally, RGB SL-PhOLEDs have been fabricated and characterized using four different emitters (red: bis(2-methyldibenzo[f,h]quinoxaline)(acetylacetonate)iridium(III)-Ir(MDQ) $2(\mathrm{acac}), \quad$ green: $\quad$ tris[2phenylpyridinato- $\mathrm{C}^{2}, N$ ]iridium(III)-Ir(ppy) ${ }_{3}$ and two blue emitters: bis(3,5-difluoro-2-(2-pyridyl)phenyl(2-carboxypyridyl) iridium(III)-FIrpic and bis(2,4-difluorophenylpyridinato)-tetrakis(1-pyrazolyl)borate iridium(III)-FIr6, see characterization of iridium complexes in Table 2 and $\mathrm{SI}$ ). It is important to mention that the blue emitter FIr6 investigated herein has been rarely used in literature (due to its high $\mathrm{E}_{\mathrm{T}}$ and 
the resulting difficulty to be hosted). Some examples are found for multi-layer PhOLEDS40,53,54 blitt âscle Online far as we know no example has been reported to date in SL-PhOLEDs using a single host (only one example exists and it involves a host:co-host system and displays low performance ${ }^{47}$ ). In this work, we manage to reach a promising Flr6-based SL-PhOLED (with SPA-2-FPOPh ${ }_{2}$ ) possessing an EQE of 9.1\% and a low $V_{\text {on }}$ below $3 \mathrm{~V}$. This may allow the development of blue SL-PhOLEDs with emission wavelengths shorter than those of the sky blue emitter FirPic. On the other hand, with notably a high EQE of $18 \%$ with FIrpic as sky blue emitter, SPA-2,7-F $\left(\mathbf{P O P h}_{2}\right)_{2}$ displays the highest overall performance in the series and demonstrates that high performance SL-PHOLEDs can be reach for all the colours with the same host material. This translates the efficiency of the association of phenylacridine and diphenylphosphineoxide units in the EML of RGB SL-PhOLEDs and its potential for the future.

\section{Synthesis}

For potential industrial applications and to reduce the environmental footprint, the synthesis of a universal host material for a SL-PhOLED should i) be short and high yielded, ii) use inexpensive starting materials and iii) avoid rare metal catalysts. The present target molecules have been synthesized following a versatile and efficient two-step route (Scheme 1). A lithium-bromine exchange was first performed on 2-bromophenyldiphenylamine followed by the trapping of the lithiated intermediate by the corresponding fluorenone, i.e. either 2,7-dibromofluorenone for $\mathbf{S P A - 2 , 7 - F}\left(\mathbf{P O P h}_{2}\right)_{2}, 3,6-$ dibromofluorenone for SPA-3,6-F(POPh $)_{2}$ or 2-bromofluorenone for SPA-2-FPOPh ${ }_{2}$. Spiro compounds SPA-2,7- $-\mathrm{FBr}_{2}, \mathrm{SPA}-3,6-\mathrm{FBr}_{2}$ and SPA-2-FBr were then obtained by cyclization (in $\mathrm{HCl} / \mathrm{AcOH}$ media) of the corresponding fluorenols (not isolated) in a high yield of $72 \%, 86 \%$ and $95 \%$. Adding $n$-BuLi to these platforms lead to a lithium-halogen exchange reaction providing the corresponding lithiated intermediates, which were trapped with chlorodiphenylphosphine to provide the corresponding diphenylphosphine compounds (not isolated), further oxidized in the presence of $\mathrm{H}_{2} \mathrm{O}_{2}$ to give SPA2,7-F(POPh $\left.{ }_{2}\right)_{2}, \mathbf{S P A}-3,6-\mathbf{F}\left(\mathbf{P O P h}_{2}\right)_{2}$ or SPA-2-FPOPh ${ }_{2}$ with a yield of $79 \%, 44 \%$ and $73 \%$ respectively. Therefore, this synthetic approach is versatile, short, very efficient (overall yield of $57 \%, 38 \%$ and $69 \%$ ), and low cost as it uses cheap starting materials (less than $0.5 € / g$ for 2-bromofluorenone, $2 € / g$ for 2,7dibromofluorenone and $4 € / g$ for 3,6-dibromofluorenone, $8 € / g$ for 2-bromophenyldiphenylamine) and no palladium catalyst. It should be mentioned that SPA-2,7-FBr $2, \mathbf{S P A - 3 , 6 - F B r} 2$ and $\mathbf{S P A - 2 - F B r}$ are appealing functional platforms, on which can be easily attached many different molecular fragments of interest for organic electronics. 


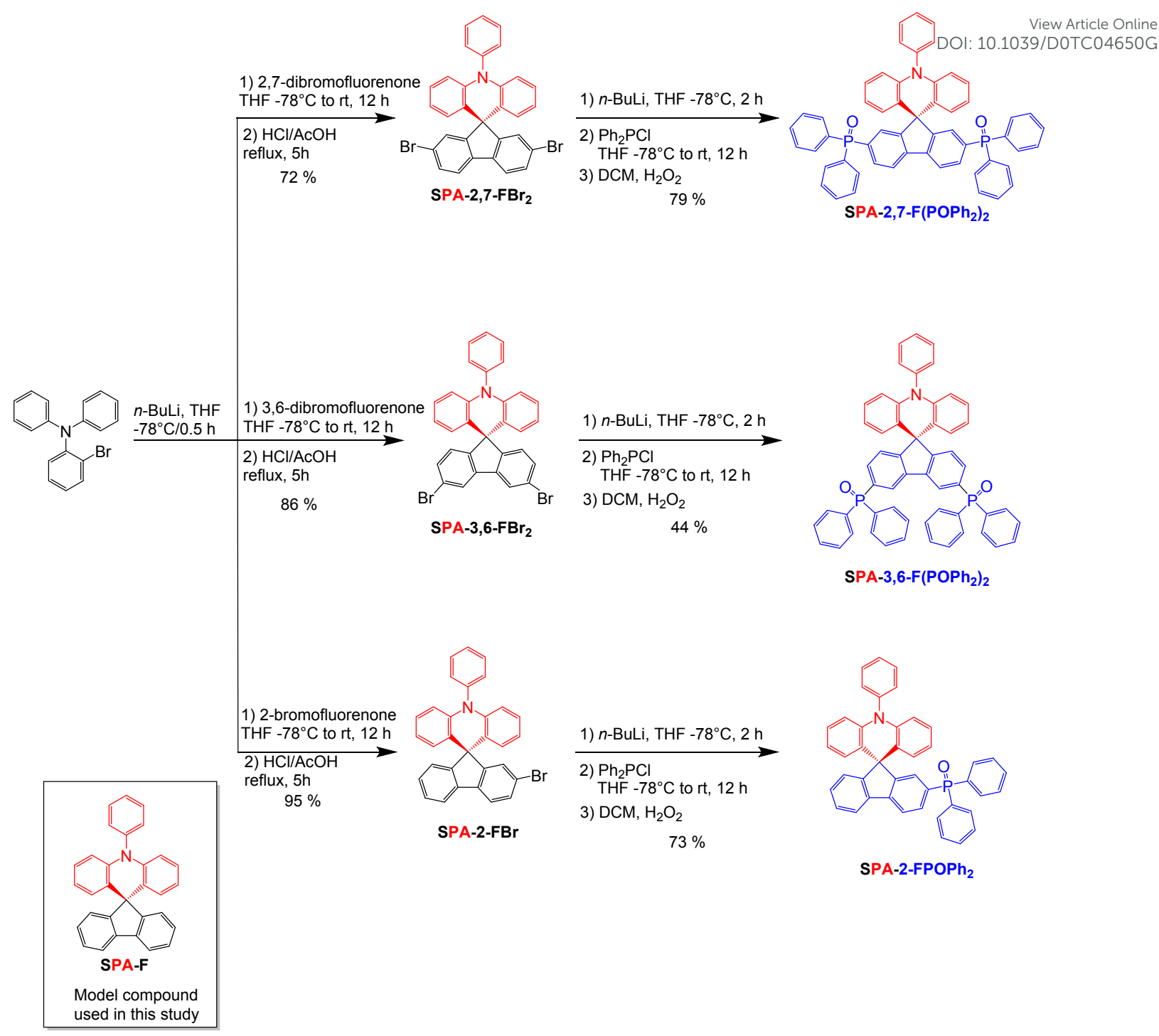

Scheme 1. Synthesis of SPA-2,7-F(POPh $)_{2}, \mathrm{SPA}-3,6-\mathrm{F}\left(\mathrm{POPh}_{2}\right)_{2}$ and $\mathrm{SPA}-2-\mathrm{FPOPh}_{2}$ and molecular structure of model compounds SPA-F

In order to precisely study the impact of the incorporation of the electron-poor units within the three compounds, their properties will be compared to those of unsubstituted model compound spirophenylacridine-fluorene SPA-F (See molecular structure in the insert of Scheme 1)..$^{33}$ Note that SPA-2,7-F $\left(\mathbf{P O P h}_{2}\right)_{2}$ and SPA-3,6-F(POPh $\left.{ }_{2}\right)_{2}$ are positional isomers, a key concept in organic chemistry, more and more used in the design of organic semi-conductors for electronics ${ }^{55,56}$ (for Organic FieldEffect Transistors, ${ }^{57-59}$ OLEDs, ${ }^{60-63}$ or Organic Photovoltaics ${ }^{64}$ ).

The electrochemical properties of SPA-2,7-F(POPh $\left.{ }_{2}\right)_{2}, \mathbf{S P A}-3,6-\mathbf{F}\left(\mathbf{P O P h}_{2}\right)_{2}, \mathbf{S P A}-2-\mathrm{FPOPh}_{2}$ and the model compound SPA-F have been investigated by cyclic voltammetry $(\mathrm{CV})$ in $\mathrm{CH}_{2} \mathrm{Cl}_{2}$ for oxidation and in DMF for reduction (Figure 1, Top); potentials are given versus a saturated calomel electrode (SCE). 

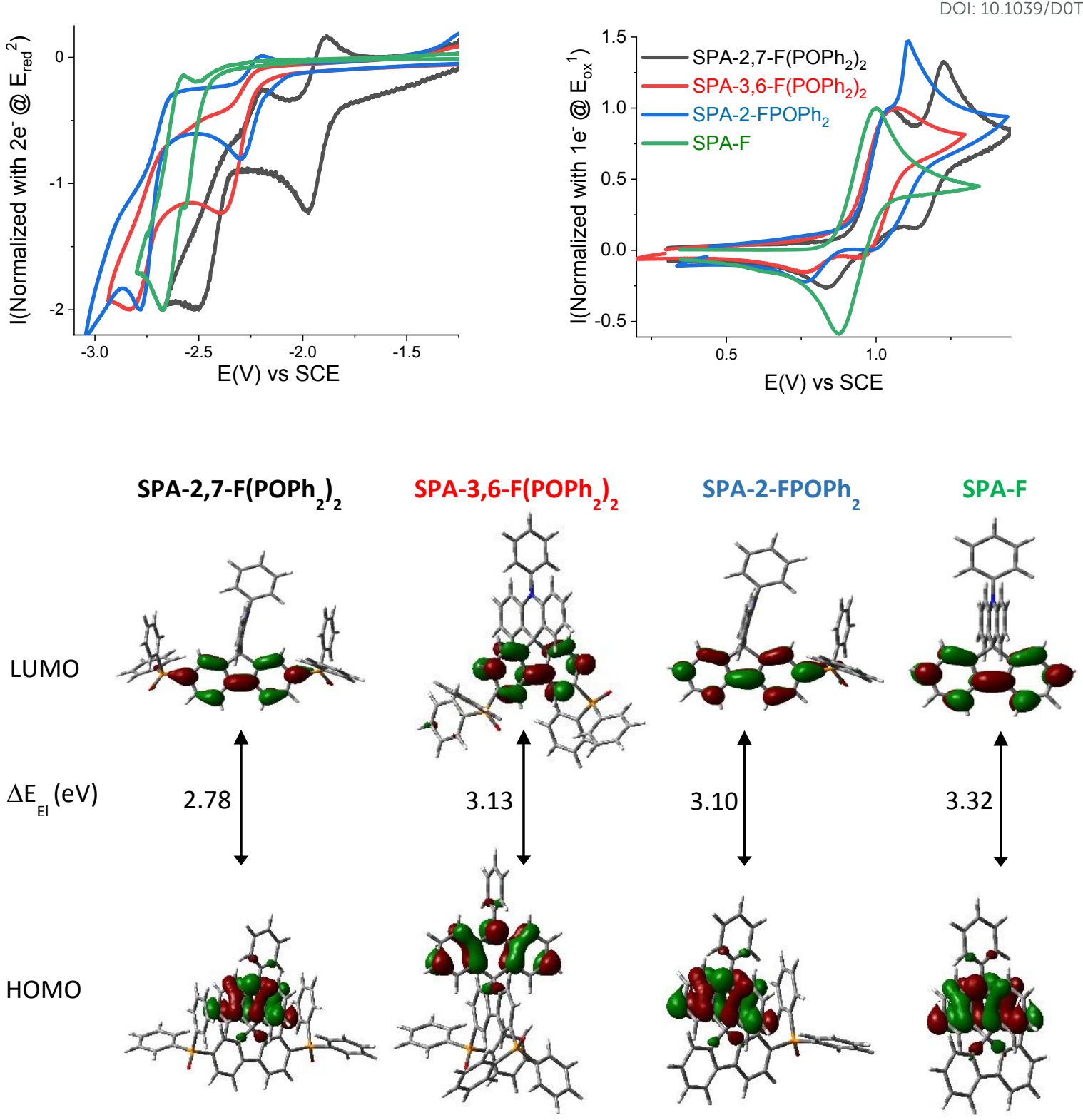

Figure 1. Top. Normalized cyclic voltammograms of SPA-2,7-F(POPh $)_{2}$ (black lines), SPA-3,6-F(POPh $\mathbf{P}_{2}$ (red lines) and SPA-2-FPOPh 2 (blue lines) and SPA-F (green lines) in the cathodic (left, DMF $+\mathrm{Bu}_{4} \mathrm{NPF}_{6}$ $0.1 \mathrm{M}$ ) or the anodic (right, $\mathrm{CH}_{2} \mathrm{Cl}_{2}+\mathrm{Bu}_{4} \mathrm{NPF}_{6} 0.2 \mathrm{M}$ ) range. Sweep-rate: $100 \mathrm{mV} . \mathrm{s}^{-1}$, platinum disk working electrode. Bottom. Frontier molecular orbitals LUMO and HOMO calculated by TD-DFT (b3lyp/6-311+G(d,p)), isovalue $0.04\left[\text { ebohr- }^{3}\right]^{1 / 2}$

In oxidation, SPA-2,7-F(POPh $\left.)_{2}, \mathbf{S P A - 3 , 6 - F ( P O P h}\right)_{2}$ and SPA-2-FPOPh $\mathbf{P}_{2}$ present three successive oxidation waves with maxima reported in Table 1 and detailed electrochemical studies presented in SI. For these three compounds, the first oxidation process is irreversible (at a sweep-rate of $100 \mathrm{mV} . \mathrm{s}^{-1}$ ) with a maximum close to $1.05 \mathrm{~V}$ (Figure 1, Top-Right). The model compound SPA-F, without any phosphine oxide attached, displays a different behaviour with a first reversible oxidation wave at 1.00 $\mathrm{V}$, being therefore shifted by $50 \mathrm{mV}$ (Figure 1,Top-Right, green line) compared to the three phosphine oxide compounds. This indicates that the phosphine oxide fragments have an influence on the reversibility of the first oxidation wave and on its potential values. Indeed, despite the separation of the donor and the acceptor units by the spiro bridge, the oxidation of the phenylacridine is influenced by the nature of the electron poor bis(diphenylphosphineoxide)-fluorene unit and appears more 
difficult to oxidize than the model compound SPA-F. However, it is noteworthy to mention thattetherie Online number and the position of the diphenylphosphine oxide units do not influenced significantly the oxidation of the phenylacridine unit as the SPA-2,7-F(POPh $)_{2}, \mathbf{S P A}-3,6-\mathbf{F}(\mathbf{P O P h})_{2}$ and SPA-2-FPOPh compounds are oxidized at similar potential values (ca $1.05 \mathrm{~V}$ ). In reduction, the results are different.

In reduction (see detailed electrochemical studies in $\mathbf{S I}$ ), SPA-2,7-F(POPh$)_{2}$ displays three successive reduction waves with maxima at $-1.98,-2.50$ and $-2.79 \mathrm{~V}$, whereas $\mathbf{S P A}-\mathbf{3}, \mathbf{6}-\mathbf{F}\left(\mathbf{P O P h} \mathbf{P}_{\mathbf{2}} \mathbf{2}_{\mathbf{2}}\right.$ only displays two reduction waves with maxima at -2.40 and $-2.83 \mathrm{~V}$ (Figure 1 , Top-Left). Contrary to SPA-2,7-F(POPh $\mathbf{P}_{2}$, which presents a first reversible reduction process, the two reduction processes of SPA-3,6-F(POPh $\mathbf{P}_{2}$ are irreversible, indicating a more reactive radical anion than for the latter. SPA-2-FPOPh $\mathbf{2}$ also displays two successive reduction waves with maxima at -2.30 and $-2.78 \mathrm{~V}$, only the first one being reversible at $100 \mathrm{mV} / \mathrm{s}$. Thus, the first reduction occurs at a different potential as a function of the number and the position of the diphenylphosphine oxide units: -1.98 V for SPA-2,7-F(POPh $\mathbf{~}_{2},-2.30 \mathrm{~V}$ for SPA-2$\mathbf{F P O P h}_{\mathbf{2}}$ and $-2.40 \mathrm{~V}$ for SPA-3,6-F(POPh $\left.)_{2}\right)_{2}$. Molecular modelling shows that this first electronic transfer is centred on the fluorene bearing the diphenylphosphine oxide units for the three compounds (see the electronic delocalization of the LUMO in Figure 1, Bottom).

The HOMO levels have been evaluated from the onset oxidation potential at $-5.26 \mathrm{eV}$ for model compound SPA-F and at -5.33 eV for both SPA-2,7-F(POPh $\mathbf{2}_{2}$ and SPA-2-FPOPh $\mathbf{F}_{\mathbf{2}}$ and at -5.31 eV for SPA-3,6-F $\left(\mathbf{P O P h}_{2}\right)_{2}$. Molecular modelling shows that the HOMO of all compounds are exclusively spread out on the acridine moiety (Figure 1, Bottom) with levels calculated at $-5.29 \mathrm{eV}$ for SPA-F, -5.55 eV for SPA-2,7-F(POPh $)_{2},-5.43 \mathrm{eV}$ for SPA-2-FPOPh $\mathbf{2}_{\mathbf{2}}$ and at -5.45 eV for SPA-3,6-F(POPh $)_{2}$. Thus, theoretical calculations confirm that, even if the donor part is localized for all four compounds on the

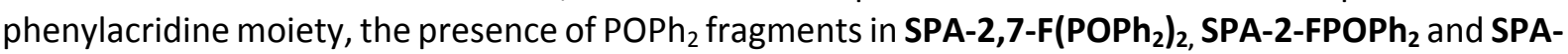
3,6-F(POPh $\left.{ }_{2}\right)_{2}$ induces a decrease of the HOMO compared to SPA-F.

The LUMO levels obtained from the onset reduction potential are respectively evaluated at -2.55 , 2.18, -2.23 and -1.94 eV for SPA-2,7-F(POPh $)_{2}$, SPA-3,6-F(POPh $)_{2}$, SPA-2-FPOPh ${ }_{2}$ and SPA-F. The same trend is also observed through theoretical calculations: -1.88, -1.51, -1.59 and -1.20 eV for SPA-2,7$\mathbf{F}(\mathbf{P O P h})_{2}$, SPA-3,6-F(POPh $)_{2}$, SPA-2-FPOPh ${ }_{2}$ and SPA-F. The values of the LUMO levels of the three compounds are lower than the one of the model compound SPA-F, because of the strong electronwithdrawing character of diphenylphosphine oxide units directly linked to the fluorene core, where the LUMO is delocalized. The difference in term of energy levels of the LUMO between SPA-2,7$\mathbf{F}(\mathbf{P O P h})_{2}, \mathbf{S P A - 3 , 6 - F}\left(\mathbf{P O P h}_{2}\right)_{2}$ and SPA-2-FPOPh $\mathbf{2}_{2}$ is assigned to both the number and the position of the phosphine oxide units. Thus, SPA-2,7-F(POPh $\left.{ }_{2}\right)_{2}$ displays the lowest LUMO energy level in the series due to the position of the phosphine oxides at $\mathrm{C} 2$ and $\mathrm{C} 7$ of the fluorene unit. Indeed, these positions allow an electronic coupling (para position of the biphenyl linkage) between the substituent and the fluorene core as previously shown in literature with other fluorene based systems..$^{55,60}$ The fluorene core is therefore strongly influenced by the inductive effect of the phenylphosphine oxides located at these positions. As only one phosphine oxide is attached at C2 of SPA-2-FPOPh $\mathbf{z}_{\mathbf{2}}$ its LUMO energy is therefore slightly higher than that of SPA-2,7-F(POPh $\left.{ }_{2}\right)_{2}$. SPA-3,6-F(POPh $\left.{ }_{2}\right)_{2}$ displays the highest LUMO energy, $-2.18 \mathrm{eV}$, in the series as the phosphine oxides, located at C3/C6 (meta position of the biphenyl linkage), have a weaker electronic effect on the fluorene backbone than at C2/C7 (para position of the biphenyl linkage). ${ }^{60}$

The electrochemical energy gap (difference between the HOMO and the LUMO energy level) of SPA2,7-F(POPh $)_{2}, \mathbf{S P A - 3 , 6 - F (}\left(\mathbf{P O P h}_{2}\right)_{2}$ and SPA-2-FPOPh${ }_{2}$ are respectively evaluated at $2.78 \mathrm{eV}, 3.13 \mathrm{eV}$ and $3.10 \mathrm{eV}$, Table 1. These gaps are all contracted compared to that of SPA-F, $(3.32 \mathrm{eV})$, however with a different magnitude, mainly due to the different LUMO energy levels of the three compounds. Thus, SPA-2,7-F $(\mathbf{P O P h})_{2}$ displays the shortest gap, followed by SPA-2-FPOPh ${ }_{2}$ and by SPA-3,6-F(POPh $\mathbf{P}_{2}$, showing that the gap can be easily controlled by the number and the position of the phosphine oxide units borne by the fluorene backbone. This gap contraction is a central point in the design of host materials for SL-PhOLEDs as an excellent injection of hole and electron is mandatory (adjustment of 
HOMO and LUMO energy levels). This feature will be discussed below in the PhOLED Viparticle Online
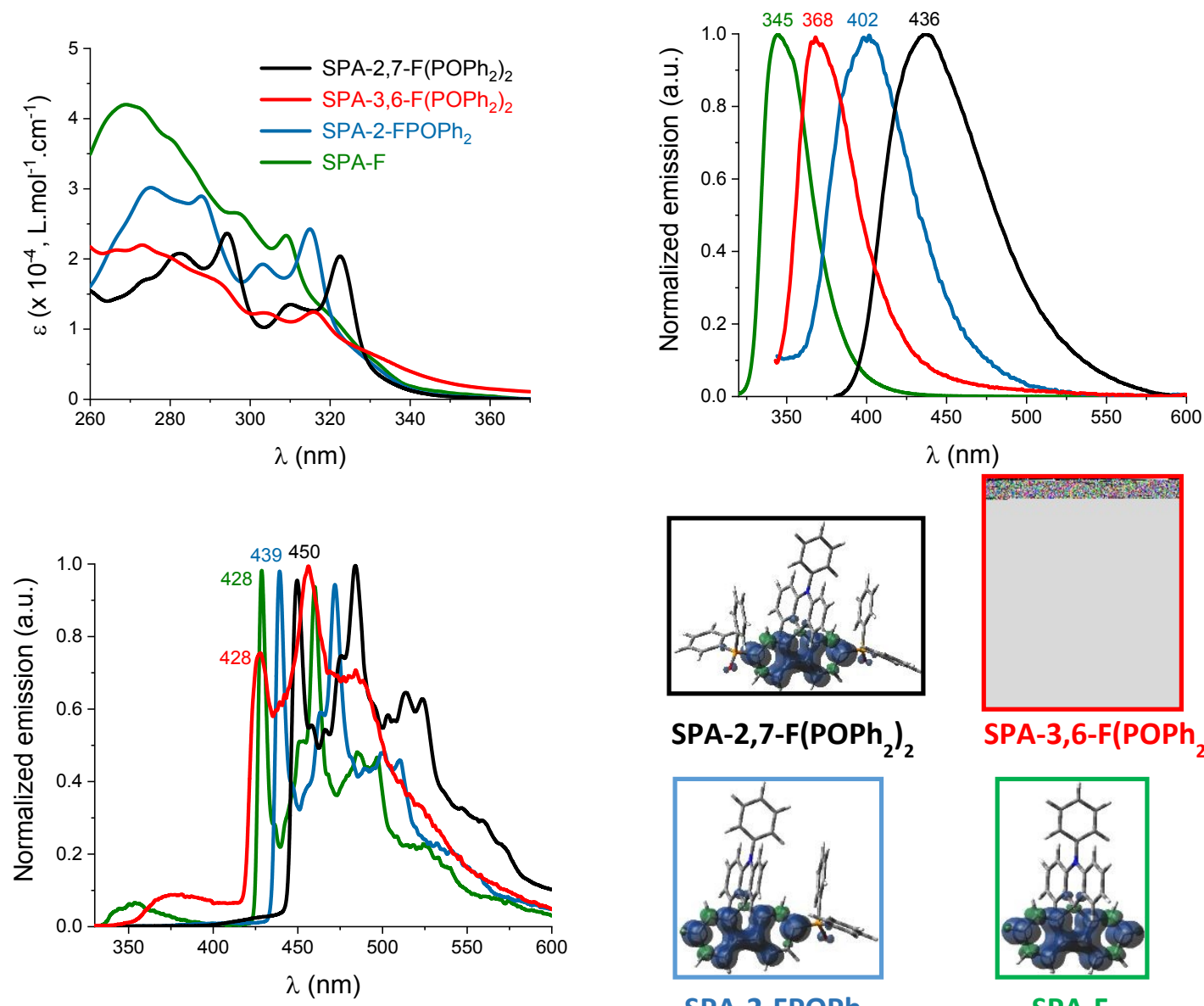
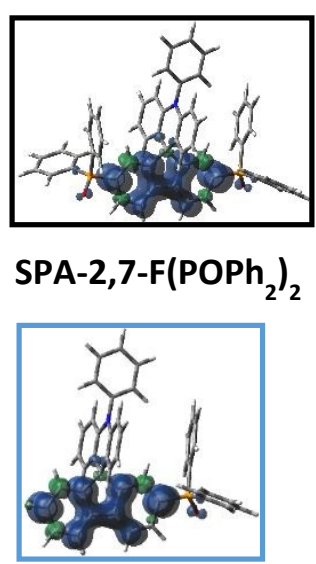

SPA-2-FPOPh

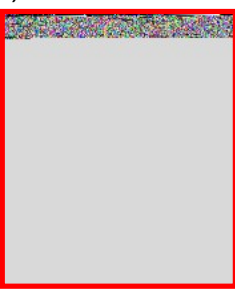

SPA-3,6-F(POPh $)_{2}$

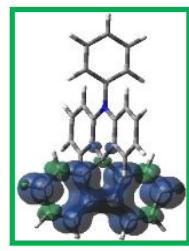

SPA-F

Figure 2. UV-Vis absorption spectra in cyclohexane (Top-Left). Normalized emission spectra at room temperature in cyclohexane, $\lambda_{\text {exc }}=310 \mathrm{~nm}$ (Top-Right). Emission spectra at $77 \mathrm{~K}$ in $2-\mathrm{MeTHF}\left(\lambda_{\mathrm{exc}}=310\right.$ $\mathrm{nm}$ ) normalized at the phosphorescence maxima (Bottom-Left). Triplet spin density distribution (TDDFT, b3lyp/6-311+g(d,p), isovalue 0.002, Bottom Right) of SPA-2,7-F(POPh $\left.{ }_{2}\right)_{2}$, (black lines) SPA-3,6-

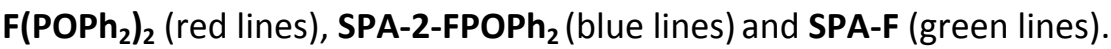

In UV-vis absorption spectroscopy (Figure 2, Top-Left), model compound SPA-F displays a small band at $309 \mathrm{~nm}$ and a long tail until $350 \mathrm{~nm}$. Thanks to Time Dependent Density Functional Theory (TD-DFT) calculations (Figure 3 ), the small band can be attributed to two transitions: HOMO to $L+5$ both localized on the acridine part $\left(\lambda_{\mathrm{th}}=305 \mathrm{~nm}\right)$ and a H-1 to LUMO both localized on the fluorene $\left(\lambda_{\mathrm{th}}=292 \mathrm{~nm}\right)$. Adding one phosphine unit at C2 of the fluorene backbone in SPA-2-FPOPh $\mathbf{P}_{2}$ induces a red shift of the main band, recorded at $315 \mathrm{~nm}$. The shift of this band confirms that the phosphorus atom is not fully insulating in such a system and that the whole $\pi$-conjugation is extended. This band can be attributed to two transitions both simulated at $304 \mathrm{~nm}$ and implying the same major contributions: a charge transfer one from the HOMO on the acridine to the $\pi^{*} L+5$ localized on the phosphine oxide fragment and a second one $\mathrm{H}-1 \rightarrow$ LUMO, with both orbitals localized on the fluorene. Adding a second phosphine oxide unit in SPA-2,7-F(POPh $\mathbf{2}_{2}$ leads to a further $8 \mathrm{~nm}$ red shift, with a band centred at $323 \mathrm{~nm}$. This band can be assigned to a transition modelized at $315 \mathrm{~nm}$ with both orbitals centred on the fluorene ( $\mathrm{H}-1 \rightarrow$ LUMO). One can note that the shape of the absorption spectra of SPA-2-FPOPh $\mathbf{F}_{\mathbf{2}}$ and SPA-2,7$\mathbf{F}(\mathbf{P O P h})_{2}$ is very similar and a characteristic of the substitution at $\mathrm{C} 2 / \mathrm{C} 7$. The absorption spectrum of SPA-3,6-F $\left(\mathbf{P O P h} \mathbf{2}_{2}\right.$ is less defined and displays lower absorption coefficients for the low energy bands. The main band is recorded at $316 \mathrm{~nm}$ indicating that shifting the phosphine oxides from the $\mathrm{C} / \mathrm{C} 7$ to the $\mathrm{C} 3 / \mathrm{C} 6$ position leads to a $7 \mathrm{~nm}$ blue shift. TD-DFT indicates that this band is due to three $\pi-\pi^{*}$ transitions: two are combinations of contributions from orbitals all localized on the fluorene, $\mathrm{H}$ - 
$1 \rightarrow \mathrm{LUMO}$ and $\mathrm{H}-1 \rightarrow \mathrm{L}+1\left(\lambda_{\mathrm{th}}=290\right.$ and $\left.299 \mathrm{~nm}\right)$, and the last transition implies orbitals on the acrididintecle Online part, HOMO $\rightarrow \mathrm{L}+8\left(\lambda_{\mathrm{th}}=314 \mathrm{~nm}\right)$. The important tail observed for SPA-3,6-F(POPh $)_{2}$ is due to several transitions at lower energies implying contributions from HOMO ( $\pi$ orbital on the acridine) to $\pi^{*}$

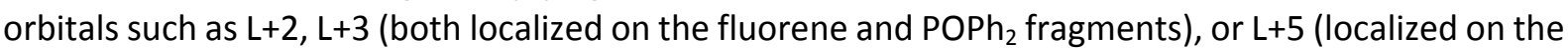
phenylacridine).

Note that the TD-DFT calculations of the four compounds show that the first excited state corresponds to a forbidden HOMO-LUMO transition, not detectable experimentally, Figure 3 . This is due to the spatial separation of HOMO and LUMO levels (HOMO localized on the acridine core and LUMO on the substituted fluorene core, Figure 3) leading to a through-space forbidden transition. ${ }^{65}$ This feature is caused by the insulating spiro bridge (despite a weak coupling exists as shown above in the electrochemical analyses) and indicates that the electronic coupling between the electron-rich unit and the electron-poor unit is efficiently restrained, which is a key point in the present design to maintain a high triplet state energy level $\mathrm{E}_{\mathrm{T}}$, as exposed below.

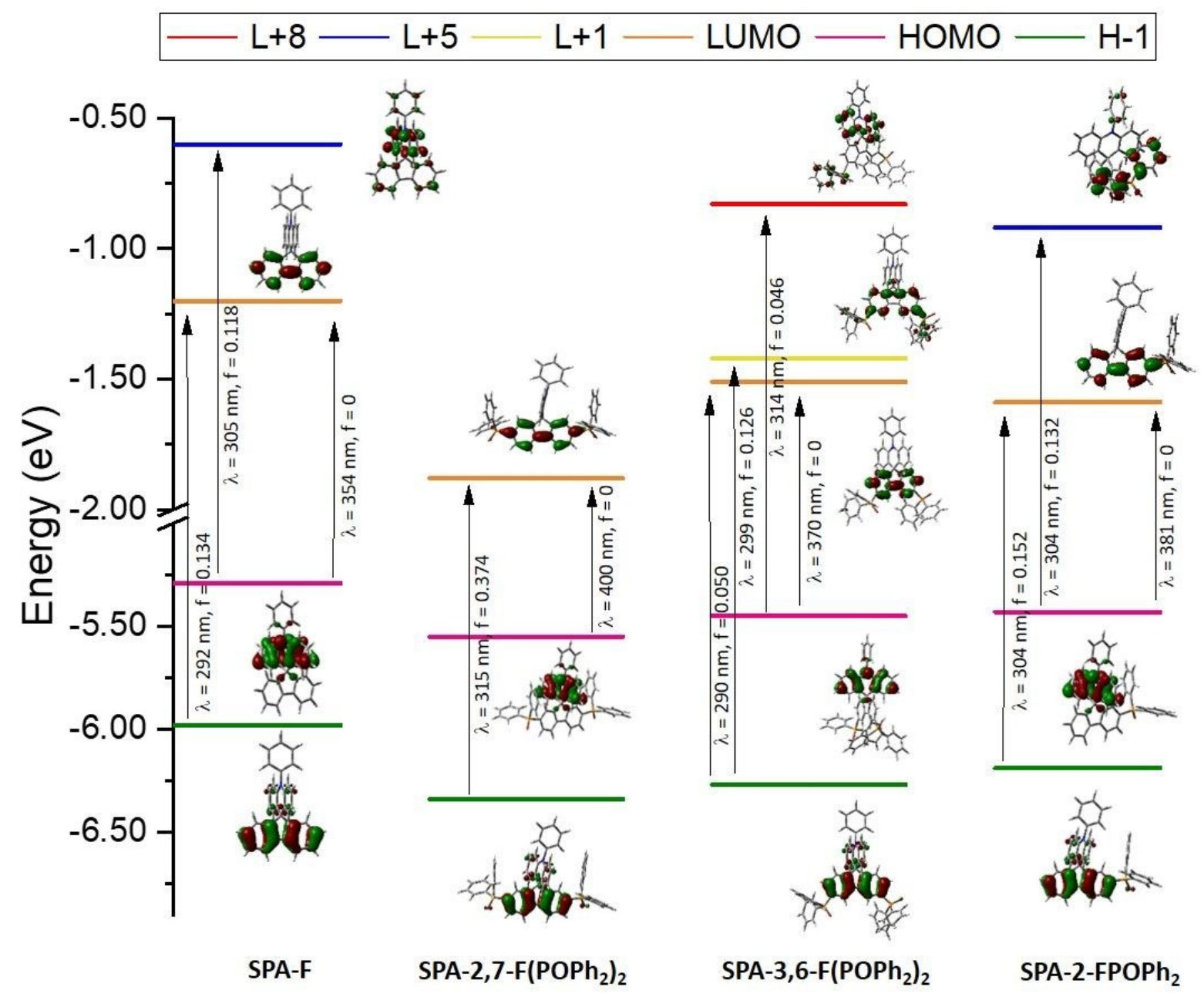

Figure 3. Representation of the energy levels and the main molecular orbitals involved in the electronic transitions of SPA-F, SPA-2,7-F(POPh $)_{2}$, SPA-3,6-F(POPh $)_{2}$ and SPA-2-FPOPh 2 obtained by TD-DFT B3LYP and the $6-311+G(d, p)$ basis set on the geometry of $S_{0}$, shown with an isovalues of 0.04 [e bohr$\left.{ }^{3}\right]^{1 / 2}$ (for clarity purpose, only the main contribution for each transition is shown, details provided in SI). 
Two features can be concluded. First, the red shift observed for SPA-3,6-F(POPh $\mathbf{~}_{2}$ compared tovsPA $\mathbf{S P c l e ~ O n l i n e}$ $\mathbf{F}$ shows that despite a meta linkage is involved in $\mathbf{S P A}-\mathbf{3}, \mathbf{6}-\mathbf{F}(\mathbf{P O P h})_{2}$, electronic coupling exists between the fluorene and the phosphine oxide units. This feature has recently been approached in literature for meta linked spirobifluorene based materials. ${ }^{10,60}$ Second, it is interesting to note that the effect of one phosphine oxide at $\mathrm{C} 2$ is similar in term of absorption wavelength to that of two at $\mathrm{C} 3 / \mathrm{C} 6$ (the two molecules have almost identical $\lambda_{\max }$ ). This shows how the absorption properties can be tuned by the number and the position of the substituents.

In fluorescence spectroscopy (cyclohexane, Figure 2-Top Right), the spectra are unresolved and we note a gradual red shift of their maxima from SPA-F $(345 \mathrm{~nm})$, SPA-3,6-F $\left(\mathbf{P O P h}_{\mathbf{2}}\right)_{\mathbf{2}}(368 \mathrm{~nm}), \mathbf{S P A - 2}$ FPOPh $_{2}(402 \mathrm{~nm})$, and to SPA-2,7-F(POPh $)_{2}(436 \mathrm{~nm})$. Thus, adding two phosphine oxides at C3/C6 in SPA-3,6-F(POPh $\left.)_{2}\right)_{2}$ leads to a significant red shift of ca $20 \mathrm{~nm}$, showing again the electronic coupling between the fluorene and the phosphine oxides. This red shift is even more pronounced, ca $60 \mathrm{~nm}$, for SPA-2-FPOPh ${ }_{2}$ due to the substitution at C2 (para position). The double substitution at C2/C7 in SPA$\mathbf{2 , 7 - F ( P O P h})_{2}$ leads to an impressive $90 \mathrm{~nm}$ shift. Also, from SPA-F to SPA-2,7-F(POPh $)_{2}$ the fluorescence band becomes larger and larger. This trend is in accordance with that highlighted in absorption but the red shifts from SPA-F to SPA-2,7-F(POPh $\mathbf{~}_{2}$ are larger due to a charge transfer character more and more important from SPA-F to SPA-2,7-F(POPh $\mathbf{~}_{2}$.

Finally, the three investigated compounds are very bad emitters with quantum yields below 0.02 (Table 1). This is in accordance with the spatial separation of HOMO and LUMO (HOMO/LUMO transition presents an oscillator strength of ca 0 , Figure 3). This characteristic is usually found in host materials for phosphors. ${ }^{65-67}$

The phosphorescent contributions evaluated thanks to the emission spectra at $77 \mathrm{~K}$ in 2-MeTHF are well resolved, very similar in shape but different in term of wavelengths. The lowest $E_{T}$ in the series is logically found for SPA-2,7-F(POPh $)_{2}, 2.76 \mathrm{eV}$, which displays a first phosphorescence contribution at $450 \mathrm{~nm}$ (Figure 2, Bottom-Left). Molecular modelling indicates that the $E_{\mathrm{T}}$ of 2,7-(POPh$)_{2}$ F-SPA is fully governed by the diphenylphosphineoxide-fluorene fragment as visualized by the triplet spin density found on the fluorene core and slightly on the phenyl units of the phosphine oxide (Figure 2, BottomRight). Removing one phosphine oxide in SPA-2-FPOPh ${ }_{2}$ increases the $E_{T}$ by $0.06 \mathrm{eV}(2.82 \mathrm{eV}, \lambda=439$ $\mathrm{nm}$ ) and concentrates the triplet spin density on the fluorene core. The highest $\mathrm{E}_{\mathrm{T}}$ in the series is found for SPA-3,6-F(POPh $)_{2}$, which displays a very high $E_{T}$ of $2.90 \mathrm{eV}(\lambda=428 \mathrm{~nm})$ due to its double meta connection. This value is identical to that of model compound SPA-F $(2.90 \mathrm{eV})$, meaning that the effect of the fluorene substitution is completely cancelled in the triplet state (note that the triplet spin density is exclusively spread out on the fluorene core, Figure 2, Bottom-Right). This result is different to that observed for $S_{1}$ but in accordance with previous reports on the different trend observed between $S_{1}$ and $T_{1}$ states. ${ }^{56,60,68}$ Indeed, it has been previously shown that meta linkages of a fluorene core lead to a red shift of both absorption and fluorescence but do not modify the first phosphorescence contribution. This interesting design strategy seems to be easily adapted to the present fluorene/phosphine oxide systems. For all compounds, the emission from $T_{1}$ state is confirmed by the very long lifetime measured at $77 \mathrm{~K}$ for these four compounds $(\tau=3.1,3.9,4.7$ and $5.6 \mathrm{~s}$ for SPA-2,7-

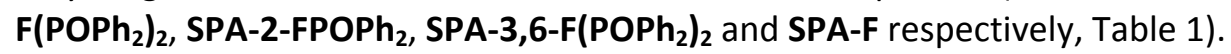

It should finally be stressed out that, at $77 \mathrm{~K}$, a very weak fluorescence contribution is observed for the three compounds SPA-2,7-F(POPh $\left.{ }_{2}\right)_{2}$, SPA-3,6-F $\left(\text { POPh }_{2}\right)_{2}$ and SPA-F and almost none for SPA-2$\mathrm{FPOPh}_{2}$. This is a different behaviour than that observed for many other host materials, in which the fluorescence is very intense at $77 \mathrm{~K} .4,69$ This feature is connected to the very low fluorescence quantum yield measured at room temperature for all compounds. Indeed, the intersystem crossing between S1 and $\mathrm{T} 1$ is favoured, and leads at $77 \mathrm{~K}$ to an intense phosphorescence contribution and a weak fluorescence contribution. ${ }^{70,71}$ Note that, in the case of SPA-2,7-F $(\mathbf{P O P h})_{2}$, the $\mathrm{S}_{1}$ and $T_{1}$ states are the closest in the series $(<0.4 \mathrm{eV})$ and the fluorescence and phosphorescence contributions are overlapped $\left(\mathrm{S}_{1}\right.$ energies have been evaluated from the onset of the emission spectra at room temperature and $T_{1}$ 
energies have been evaluated from the peak maximum at $77 \mathrm{~K}$ as often found in literature $\left.{ }^{72}\right)$. This $15 \mathrm{w} / \mathrm{T}_{1}^{\mathrm{ticle}}$ Online gap increases by shifting the phosphine oxide units from C2/C7 to C3/C6 (0.7 eV for SPA-3,6-F(POPh $\left.\mathbf{P}_{2}\right)$ or by removing one phosphine oxide unit (0.6 eV for SPA-2-FPOPh $\mathbf{2}_{2}$ or two (0.9 eV for SPA-F). In fact, both $\mathrm{S} 1$ and $\mathrm{T} 1$ states decrease upon conjugation expansion, with a significantly more important effect on the S1 states compared to T1 states. This is why, in the case of the highly conjugated SPA-2,7$\mathbf{F}\left(\mathrm{POPh}_{\mathbf{2}}\right)_{2}$, the $\mathrm{S} 1$ state decreases close to the $\mathrm{T} 1$ state.

Table 1. Selected electronic and physical data

\begin{tabular}{|c|c|c|c|c|}
\hline & SPA-2,7-F(POPh $)_{2}$ & SPA-3,6-F(POPh $)_{2}$ & SPA-2-FPOPh & SPA-F \\
\hline $\begin{array}{c}\lambda_{\text {abs } \max }[\mathrm{nm}]^{\mathrm{a}} \\
\left(\varepsilon \times 10^{4}[\text { L.mol }\right. \\
\left.\left.{ }^{1} . \mathrm{cm}^{-1}\right]\right)\end{array}$ & $\begin{array}{c}323(2.0) ; 310(1.3) ; \\
295(2.4) ; 283(2.1) ; \\
274(1.7)\end{array}$ & $\begin{array}{c}316(1.2) ; 304(1.2) ; \\
273(2.2)\end{array}$ & $\begin{array}{c}315(2.5) ; 310(1.3) ; \\
295(2.4) ; 283(2.1) ; \\
274(1.7)\end{array}$ & 309 (2.4) \\
\hline$\lambda_{\text {em fluo }}[\mathrm{nm}]^{\mathrm{a}}$ & 436 & 368 & 402 & 345 \\
\hline $\mathrm{E}_{\mathrm{S}}[\mathrm{eV}]^{\mathrm{c}}$ & 3.15 & 3.58 & 3.43 & 3.77 \\
\hline QY $^{\mathrm{a}}$ & $<0.01$ & $<0.01$ & 0.02 & nd \\
\hline$\lambda_{\text {em phospho }}[\mathrm{nm}]^{\mathrm{b}}$ & 450 & 428 & 439 & 428 \\
\hline $\mathrm{E}_{\mathrm{T}}[\mathrm{eV}]^{\mathrm{b}, \mathrm{d}}$ & 2.76 & 2.90 & 2.82 & 2.90 \\
\hline $\mathrm{E}_{\mathrm{S}^{-}} \mathrm{E}_{\mathrm{T}}[\mathrm{eV}]$ & 0.39 & 0.68 & 0.61 & 0.87 \\
\hline$\tau_{p}[s]\left(\lambda_{e m}[n m]\right)^{b}$ & $3.1(450)$ & $4.7(428)$ & 3.9 (439) & $5.6(428)$ \\
\hline$E_{o x}(V)^{e, f}$ & $1.06,1.23,2.18$ & $1.07,2.25$ & $1.04(\mathrm{sh}), 1.11,>2.2$ & $1.00,1.77,2.20$ \\
\hline $\mathrm{E}_{\mathrm{red}}(\mathrm{V})^{\mathrm{e}, \mathrm{g}}$ & $-1.98,-2.50,-2.79$ & $-2.40,-2.83$ & $-2.30,-2.78$ & $-2.56,-2.67$ \\
\hline HOMO $(e V)^{\mathrm{h}}$ & -5.33 & -5.31 & -5.33 & -5.26 \\
\hline LUMO $(\mathrm{eV})^{\mathrm{h}}$ & -2.55 & -2.18 & -2.23 & -1.94 \\
\hline$\Delta \mathrm{E}_{\mathrm{el}}(\mathrm{eV})^{\mathrm{i}}$ & 2.78 & 3.13 & 3.10 & 3.32 \\
\hline$\mu_{\mathrm{h}+}\left(\mathrm{cm}^{2} / \mathrm{V} . \mathrm{s}\right)^{\mathrm{j}}$ & $8.2 \times 10^{-6}$ & $1.4 \times 10^{-8}$ & $1.9 \times 10^{-7}$ & $1 \times 10^{-5}$ \\
\hline$\mu_{\mathrm{e}-}\left(\mathrm{cm}^{2} / \mathrm{V} . \mathrm{s}\right)^{\mathrm{j}}$ & $2 \times 10^{-4}$ & $3.1 \times 10^{-6}$ & $1.3 \times 10^{-5}$ & - \\
\hline $\mathrm{T}_{d}\left({ }^{\circ} \mathrm{C}\right)^{\mathrm{k}}$ & 474 & 411 & 381 & 286 \\
\hline $\mathrm{T}_{g}\left({ }^{\circ} \mathrm{C}\right)^{\prime}$ & 143 & 165 & 118 & 90 \\
\hline $\mathrm{T}_{c}\left({ }^{\circ} \mathrm{C}\right)^{\mathrm{I}}$ & 218 & - & 191 & 141 \\
\hline
\end{tabular}

a. in cyclohexane at RT, $\lambda_{\text {exc }}=310 \mathrm{~nm}$; b. in 2-MeTHF at $77 \mathrm{~K}, \lambda_{\text {exc }}=310 \mathrm{~nm}$; c. from fluorescence onset at RT; $d$. from first phosphorescence peak, e. vs SCE; f. in $\mathrm{CH}_{2} \mathrm{Cl}_{2}$; g. in DMF; h. from electrochemical data; i. $\Delta \mathrm{E}_{\mathrm{e}}=\mid \mathrm{HOMO}-$ LUMO|; j. determined from SCLC devices analysis; $k$. determined by TGA; l. determined by DSC ( $2^{\text {nd }}$ heating), nd: not determined.

The thermal properties have been studied by thermogravimetric analyses (TGA, see SI) and differential scanning calorimetry (DSC, Figure 4). Due to the presence of the rigid spiro bridge and bulky diphenylphosphine oxides, SPA-2,7-F(POPh $\left.{ }_{2}\right)_{2}, \mathbf{S P A - 3 , 6 - F}\left(\mathbf{P O P h}_{2}\right)_{2}$ and SPA-2-FPOPh $\mathbf{P}_{2}$ display higher decomposition temperature $\mathrm{T}_{d}\left(5 \%\right.$ mass loss) than unsubstituted SPA-F $\left(\mathrm{T}_{d}=286^{\circ} \mathrm{C}\right)$. The highest $\mathrm{T}_{d}$ is recorded for SPA-2,7-F(POPh$\left.)_{2}\right)_{2}$ at ca $474^{\circ} \mathrm{C}$ (See SI). The positive influence of the diphenylphosphine oxide units on the thermal properties is confirmed by DSC. Thus, during the $2^{\text {nd }}$ heating run (between

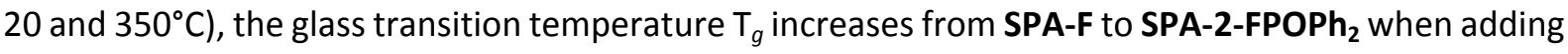
one phosphine oxide ( 90 vs $118{ }^{\circ} \mathrm{C}$, Figure 4). The $T_{g}$ are even much increased when two phosphine oxides are present within the molecular structure, $143^{\circ} \mathrm{C}$ for SPA-2,7-F(POPh $)_{2}$ and $165^{\circ} \mathrm{C}$ for SPA-3,6$\mathbf{F}\left(\mathrm{POPh}_{2}\right)_{2}$. One can hence note that the positions $\mathrm{C} 3 / \mathrm{C} 6$ provide the material with the highest $\mathrm{T}_{g}$.

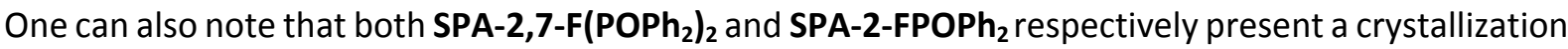
temperature $T_{c}$ at ca 218 and $191^{\circ} \mathrm{C}$ (during the $2^{\text {nd }}$ heating cycle), also observed for SPA-F but at a much lower temperature, i.e. $141^{\circ} \mathrm{C}$ (Figure 4). Thus, incorporating one or two diphenylphosphine oxide units in $\mathrm{C} 2 / \mathrm{C} 7$ allows to significantly increase the $\mathrm{T}_{c}$. The substitution at meta positions (C3/C6) 
of SPA-3,6-F(POPh $)_{2}$ leads to a different result as neither $\mathrm{T}_{c}$ nor $\mathrm{T}_{\mathrm{m}}$ (melting) transitions are obseriryedcle Online during the $2^{\text {nd }}$ heating cycle, of great interest for further OLED applications.

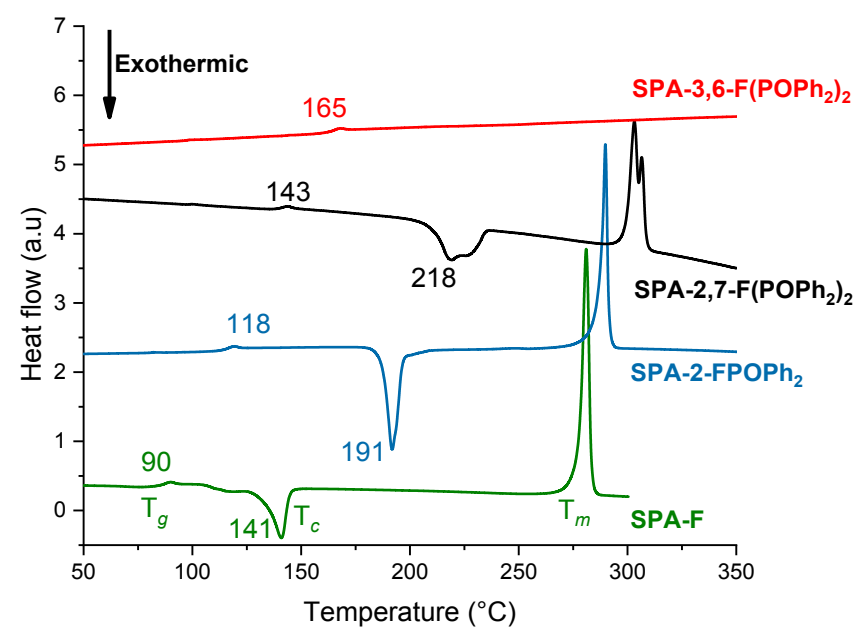

Figure 4. DSC traces ( $2^{\text {nd }}$ heating) of SPA-2,7-F(POPh $)_{2}$ (black line), SPA-3,6-F(POPh $)_{2}$ (red line), SPA2-FPOPh ${ }_{2}$ (blue line) and SPA-F (green line).

The device architecture simplification, by removing interfacial layers, requires that the host matrix can efficiently act simultaneously as hole and electron charge carrier. In order to allow recombination of opposite charges within the EML, it is moreover necessary to have a good balance between hole and electron carrier mobilities. Otherwise, excitons are created near an electrode, which increases the quenching rate due to non-radiative recombination. In this respect, the charge transport property characterization is mandatory in order to rationalize the structure - device efficiency relationship in these host materials for PhOLED applications. As PhOLEDs are vertical devices, space charge limited current (SCLC) devices appear to be the most appropriate devices to probe the charge carrier mobilities. Indeed, by elaborating hole-only and electron-only devices, one can access the out-of-plane hole and electron mobilities respectively (see SI for composition and elaboration details).

The hole/electron mobility $\left(\mu_{\mathrm{h}} / \mu_{\mathrm{e}}\right)$ of SPA-2,7-F(POPh $\left.{ }_{2}\right)_{2}, \mathbf{S P A - 2 - F P O P h}$, and SPA-3,6-F $\left(\mathbf{P O P h}_{2}\right)_{2}$ have been estimated to be $8.2 \times 10^{-6} / 2 \times 10^{-4} \mathrm{~cm}^{2} / \mathrm{V} . \mathrm{s}, 1.9 \times 10^{-7} / 1.3 \times 10^{-5} \mathrm{~cm}^{2} / \mathrm{V}$.s and $1.4 \times 10^{-8} / 3.1 \times 10^{-6}$ $\mathrm{cm}^{2} /$ V.s, respectively (Figure 5). One can first interestingly note that the electron mobility is higher than that of hole for the three hosts studied herein. This is a key point as it allows to balance the hole transporting nature of the iridium complexes (FIrpic, ${ }^{73} \operatorname{Ir}(\mathrm{ppy})_{3}{ }^{74}$ no data found in literature for $\left.\operatorname{Ir}(\mathrm{MDQ})_{2}(\mathrm{acac})\right)$. It is always awkward to explain trends in mobility values from a series of molecules. However, one can note that SPA-2,7-F(POPh$)_{2}$, which is the molecule with the larger conjugation (compared to SPA-3,6-F(POPh $)_{2}$ ), the greatest symmetry (compared to SPA-2-FPOPh ${ }_{2}$ ), and the highest electron affinity (ie lowest LUMO level), exhibits the highest electron and hole mobilities. With a single phosphine oxide unit, SPA-2-FPOPh ${ }_{2}$ exhibits both structural asymmetry and lower electron affinity. As a consequence, both mobilities decrease by more than one order of magnitude. Finally, SPA-3,6-F(POPh $\left.{ }_{2}\right)_{2}$ has the lowest charge carrier mobilities. This is in good agreement with the amorphous nature of this derivative, as shown by DSC analysis.

In addition, if we consider the mobility balance between electrons and holes $\left(\mu_{\mathrm{e}} / \mu_{\mathrm{h}}\right)$ in each molecule, calculated at ca 24, 68 and 221 for SPA-2,7-F(POPh $)_{2}, \mathbf{S P A}-2-\mathbf{F P O P h}$, and SPA-3,6-F(POPh $)_{2}$, 
respectively, SPA-2,7-F(POPh $\mathbf{~}_{\mathbf{2}}$ appears clearly as the most suitable candidate to transport ch chirgersicle Online into a PhOLED device.
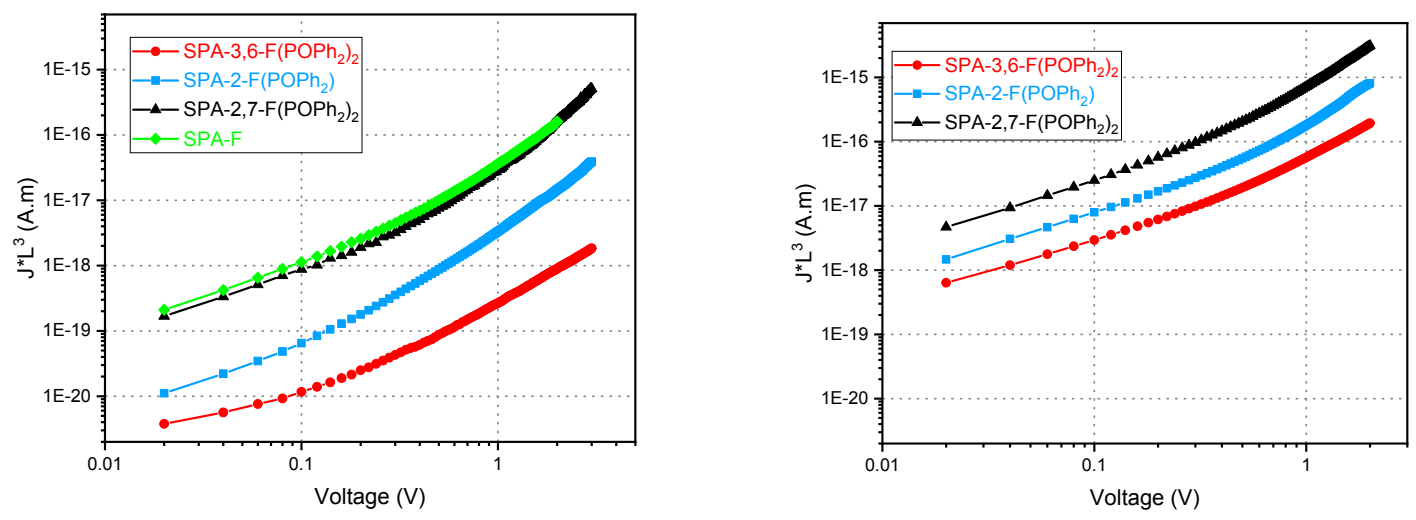

Figure 5. Thickness-scaled current voltage characteristics of SPA-2,7-F(POPh $\mathbf{~}_{\mathbf{2}}$ (blue lines), SPA-3,6$\mathbf{F}\left(\mathbf{P O P h}_{2}\right)_{2}$ (red lines), SPA-2-FPOPh $\mathbf{h}_{2}$ (black lines) and SPA-F (green lines) hole-(Left) and electron-only (Right) SCLC devices.

The different molecules were finally incorporated as host in red, green and blue SL-PhOLEDs using as emitter either $\operatorname{Ir}(\mathrm{MDQ})_{2}(\mathrm{acac})$ for red emission, $\operatorname{Ir}(\mathrm{ppy})_{3}$ for green emission, and FIrpic or FIr6 for blue emission (Tables 2 and 3, Figures 6 and 7). The SL-PhOLED architecture is the following: ITO/PEDOT:PSS $(40 \mathrm{~nm}) /$ EML (Host+Guest 10\% wt) $(100 \mathrm{~nm}) / \mathrm{LiF}(1.2 \mathrm{~nm}) / \mathrm{Al}(100 \mathrm{~nm})$ with ITO/PEDOT:PSS as anode and LiF/Al as cathode.

First, the four iridium complexes have been studied in strictly identical conditions in order to precisely determine their electronic properties and particularly their HOMO and LUMO energy levels and $E_{T}$ (Table 2). It is important to mention that many data can be found in literature for these phosphors but recorded in different experimental conditions (FIrpic, $\left.{ }^{73} \operatorname{Ir}(\mathrm{ppy})_{3},{ }^{75,}{ }^{76} \mathrm{FIr6},{ }^{77} \operatorname{Ir}(\mathrm{MDQ})_{2}(\mathrm{acac})^{78,}{ }^{79}\right)$. This heterogeneity renders the comparison with host materials and between them difficult. In the case of SL-PhOLED, studying both host materials and phosphors in identical experimental conditions appear particularly important.

Thus, in 2-MeTHF at room temperature, the $E_{\mathrm{T}}$ of $\operatorname{Ir}(\mathrm{MDQ})_{2}(\mathrm{acac}), \operatorname{Ir}(\mathrm{ppy})_{3}$, FIrpic and $\mathrm{FIr} 6$ have been evaluated at 2.02, 2.43, 2.67 and $2.72 \mathrm{eV}$ respectively from the maximum of first emission peak. At 77 $\mathrm{K}$ in a frozen 2-MeTHF matrix (in the same conditions than those used to measure the $E_{T}$ of the hosts), there is a blue shift of the emission spectra (Table 2) due to the decrease of molecular motions and the $\mathrm{E}_{\mathrm{T}}$ are therefore slightly increased at $2.08,2.51,2.72$ and $2.76 \mathrm{eV}$. In thin films, dispersed into the host materials studied herein (corresponding to the EML of the devices studied below), the spectra are red shifted and the $E_{T}$ are measured at 1.97, 2.40, 2.63 and $2.70 \mathrm{eV}$ (note that the spectra of each complex are independent of the matrix used, see SI). In these conditions, the thin-film spectra appear to be identical to the electroluminescent (EL) spectra presented below, showing the similitude of the optical processes involved.

The HOMO/LUMO of $\operatorname{Ir}(\mathrm{MDQ})_{2}(\mathrm{acac})$, $\left.\operatorname{Ir}(\mathrm{ppy})_{3}\right)$, FIrpic and FIr6 have also been evaluated by electrochemical analyses in solution (in $\mathrm{CH}_{2} \mathrm{Cl}_{2}+\mathrm{Bu}_{4} \mathrm{NPF}_{6} 0.2 \mathrm{M}$, see $\mathrm{CV}$ in $\mathrm{SI}$ ) at -5.26/-2.91, -4.97/$2.19,-5.55 /-2.52,-5.66 /-2.32 \mathrm{eV}$. These data are particularly interesting to interpret the device performance presented below.

Table 2. Selected electronic and physical data of the four iridium complexes investigated

\begin{tabular}{|l|c|c|c|c|}
\hline & $\operatorname{Ir}(\mathrm{MDQ})_{2}(\mathrm{acac})$ & $\operatorname{Ir}(\mathrm{ppy})_{3}$ & FIrpic & FIr6 \\
\hline
\end{tabular}




\begin{tabular}{|c|c|c|c|c|}
\hline$\lambda_{\mathrm{em}}[\mathrm{nm}]^{\mathrm{a}} \mathrm{rt} / 77 \mathrm{~K} / \mathrm{film}^{\mathrm{b}}$ & 613 / 597 / 630 & $511 / 493$ / 517 & 465 / 456 / 471 & $456 d 449 d 3^{4} 60^{\text {arti }}$ \\
\hline $\mathrm{E}_{\mathrm{T}}[\mathrm{eV}]^{\mathrm{a}, \mathrm{c}} \mathrm{RT} / 77 \mathrm{~K} / \mathrm{film}^{\mathrm{b}}$ & $2.02 / 2.08 / 1.97$ & $2.43 / 2.51 / 2.40$ & $2.67 / 2.72 / 2.63$ & $2.72 / 2.76 / 2.70$ \\
\hline$E_{o x}(V)^{d, e}$ & $0.96,1.67$ & $0.69,1.74$ & $1.28,1.80$ & $1.4(\mathrm{sh}), 1.56$ \\
\hline$E_{\text {red }}(V)^{d, e}$ & $-1.68(\mathrm{sh})$ & no distinct wave & -2.04 & $-2.40(\mathrm{sh})$ \\
\hline HOMO $(\mathrm{eV})^{f}$ & -5.26 & -4.97 & -5.55 & -5.66 \\
\hline LUMO $(e V)^{f}$ & -2.91 & -2.19 & -2.52 & -2.32 \\
\hline$\Delta \mathrm{E}_{\mathrm{el}}(\mathrm{eV})^{\mathrm{g}}$ & 2.35 & 2.78 & 3.03 & 3.34 \\
\hline
\end{tabular}

a. in 2-MeTHF , $\lambda_{\text {exc }}=310 \mathrm{~nm}$; b. dispersed in the host materials, either in SPA-2,7-F(POPh $\mathbf{~}_{2}, \mathbf{S P A}-\mathbf{2}-\mathbf{F P O P h}$, or SPA-3,6-F(POPh $)_{2}$, c. from first phosphorescence peak, d. onset potential vs SCE; e. in $\mathrm{CH}_{2} \mathrm{Cl}_{2}$; f. from electrochemical data (onset oxidation or reduction potentials) ; g. $\Delta \mathrm{E}_{\mathrm{el}}=|\mathrm{HOMO}-\mathrm{LUMO}|$

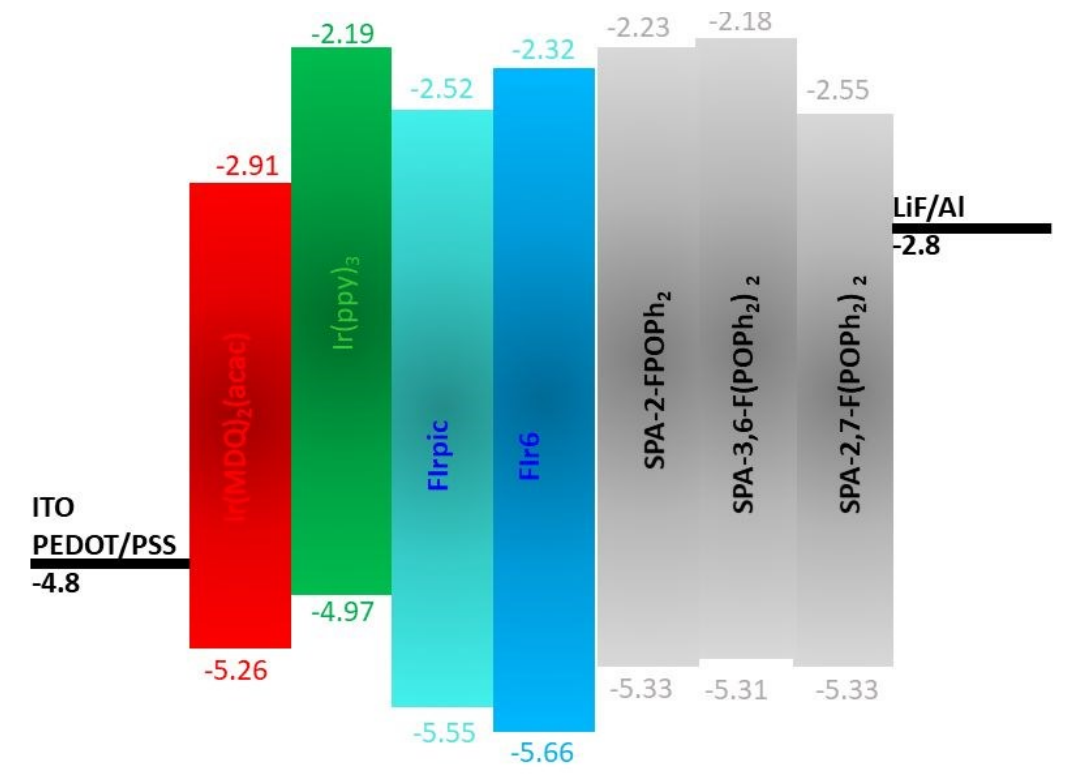

Figure 6. Schematic energy diagrams of the different components used in the EML of the present SLPhOLEDs.

First, the phosphor $\operatorname{Ir}(\mathrm{MDQ})_{2}$ (acac) $\left(\mathrm{HOMO}=-5.26 / \mathrm{LUMO}=-2.91 \mathrm{eV}, \mathrm{E}_{\mathrm{T}}=1.97 \mathrm{eV}\right.$ dispersed in the present hosts, Table 2) has been used as red-emitting dopant in SL-PhOLEDs. The best performance has been obtained with SPA-2,7-F(POPh $\mathbf{~}_{2}$ as host reaching a maximum EQE of $8.7 \%$. The best device reaches a maximum luminance $L$ of $6843 \mathrm{~cd} . \mathrm{m}^{-2}$ at $170 \mathrm{~mA} / \mathrm{cm}^{2}$ showing a good stability at high current density. The two other hosts SPA-3,6-F(POPh $)_{2}$ and $\mathbf{S P A - 2 - F P O P h}{ }_{2}$, studied in strictly identical experimental conditions display lower performance with low EQE of ca $5 \%$, Table 3 . This can be related to the strong difference observed in term of charge carrier mobilities as exposed above. Indeed, the hole and electron mobilities of SPA-2,7-F(POPh $)_{2}$ are not only significantly higher than those of both SPA-3,6-F $\left(\mathbf{P O P h}_{2}\right)_{2}$ and SPA-2-FPOPh ${ }_{2}$ but also more balanced. When the charge transport is not balanced, the recombination zone is located close to the metal electrodes, thereby causing exciton quenching by the electrodes and reducing the device efficiency. This feature is surely at the origin of the higher device performance observed for red SL-PhOLEDs using SPA-2,7-F(POPh $\mathbf{P}_{\mathbf{2}}$ as host. This will be confirmed with the other dopants presented below. On the other hand, the very low LUMO level of $\operatorname{Ir}(\mathrm{MDQ})_{2}(\mathrm{acac}),-2.91 \mathrm{eV}$, is also involved in the moderate performance observed for the three hosts, the host possessing the lowest LUMO, i.e. SPA-2,7-F $\left(\mathbf{P O P h}_{2}\right)_{2} / L U M O=-2.55 \mathrm{eV}$ leading to the highest performance. The three devices also display a different threshold voltage $\left(\mathrm{V}_{\text {on }}\right): 2.8 \mathrm{~V}$ for SPA-2,7$\mathbf{F}(\mathbf{P O P h})_{2}, 3.2 \mathrm{~V}$ for SPA-2-FPOPh ${ }_{2}$ and 3.6 V for SPA-3,6-F(POPh $)_{2}$, translating (i) the different charge injections within the devices. This is in accordance with the different energy gaps observed for the three compounds (2.78 eV for SPA-2,7-F(POPh $)_{2}, 3.10 \mathrm{eV}$ for SPA-2-FPOPh $\mathbf{P}_{2}$ and 3.13 V for SPA-3,6$\mathbf{F}(\mathbf{P O P h})_{2}$ the lowest gap leading to the lowest $V_{\text {on }}$ and herein to the highest EQE. The different $V_{\text {on }}$ can 
also be related to the different $\mu_{\mathrm{e}} / \mu_{\mathrm{h}}$ ratio of the hosts, the highest $\mu_{\mathrm{e}} / \mu_{\mathrm{h}}$ leading to the highest Vew Aricle Online the case of SPA-3,6-F(POPh $\left.{ }_{2}\right)_{2}$, and the lowest $\mu_{\mathrm{e}} / \mu_{\mathrm{h}}$ leading to the lowest $\mathrm{V}_{\text {on }}$ in the case of SPA-2,7$\mathbf{F}\left(\mathrm{POPh}_{2}\right)_{2}$.

The green SL-PhOLEDs have been then studied in a similar way using the classical green emitter $\operatorname{Ir}(\mathrm{ppy})_{3}$ $\left(\mathrm{HOMO}=-4.97 \mathrm{eV}, \mathrm{LUMO}=-2.19 \mathrm{eV}, \mathrm{E}_{\mathrm{T}}=2.40 \mathrm{eV}\right.$ dispersed in the present hosts, Table 2). Usually, green-emitting SL-PhOLEDs display the highest performances (compare to blue and red) as green phosphors are usually the easiest to host in a PhOLED. The difference in term of performances between the three hosts is less marked than for the red phosphor. Indeed, if the highest performance has been again reached with SPA-2,7-F(POPh $\left.{ }_{2}\right)_{2}$, the two other host materials also display interesting performances. The lowest efficiency is recorded for SPA-2-FPOPh $\mathbf{H}_{2}$, which displays a maximal EQE of $10.4 \%$, and corresponding CE of $35.6 \mathrm{~cd} / \mathrm{A}$ and $\mathrm{PE}$ of $32.9 \mathrm{Im} / \mathrm{W}$ at $0.02 \mathrm{~mA} / \mathrm{cm}^{2}$ (Table 3). The performances are increased with SPA-3,6-F(POPh $)_{2}$ as a high maximal EQE of $13.9 \%$ and corresponding CE of $52.0 \mathrm{~cd} / \mathrm{A}$ and $\mathrm{PE}$ of $38.9 \mathrm{Im} / \mathrm{W}$ (at $0.03 \mathrm{~mA} / \mathrm{cm}^{2}$ ) are recorded. The best performance is finally obtained with SPA-2,7-F(POPh $\mathbf{2}_{2}$ as host with a maximal EQE of $16.4 \%$, and corresponding CE of $56.3 \mathrm{~cd} / \mathrm{A}$ and $\mathrm{PE}$ of $53.6 \mathrm{Im} / \mathrm{W}$ at $0.04 \mathrm{~mA} / \mathrm{cm}^{2}$ (Table 3). A maximum luminance of $38970 \mathrm{~cd} \cdot \mathrm{m}^{-2}$ at $180 \mathrm{~mA} / \mathrm{cm}^{2}$ is reached, translating a high performance and a good stability at high current density. In accordance with the data exposed above for the red phosphor, SPA-2,7-F(POPh $\mathbf{P}_{2}$ displays the lowest $V_{\text {on }}$ in the series, $2.3 \mathrm{~V}$ due to its most contracted gap and lowest $\mu_{\mathrm{e}} / \mu_{\mathrm{h}}$ in the series. During the writing of this manuscript, Isobe and coworkers have reported green SL-PhOLEDs with a higher EQE, overpassing $20 \% .^{34}$

Blue phosphors are the most difficult to host and blue-emitting PhOLEDs remain the weakest link of the technology. ${ }^{5}, 18,42,68,80-82$ In this work, two blue phosphors have been used: the classical sky blue emitter FIrpic ( $\mathrm{HOMO}=-5.55 \mathrm{eV} / \mathrm{LUMO}=-2.52 \mathrm{eV}, \mathrm{E}_{\mathrm{T}}=2.63 \mathrm{eV}$ dispersed in the present hosts, Table 2) and the barely studied blue emitter FIr6 ( $\mathrm{HOMO}=-5.66 \mathrm{eV} / \mathrm{LUMO}=-2.32 \mathrm{eV}, \mathrm{E}_{\mathrm{T}}=2.70 \mathrm{eV}$ dispersed in the present hosts, Table 2). Usually, when both the HOMO/LUMO gap and $E_{T}$ of the phosphor increase, the PhOLED efficiency dramatically drops. In a multi-layer PhOLED, this can be compensate by the transporting and blocking layers but in single-layer device, this is far more difficult. To the best of our knowledge, only a few examples of blue SL-PhOLEDs (using a single host) is reported and all of them use the sky blue emitter FIrpic. ${ }^{24,35-37,83}$ Indeed, the other blue dopants found in OLEDs literature, for example FCNIrpic (HOMO $=-5.87 \mathrm{eV} / \mathrm{LUMO}=-2.65 \mathrm{eV}$, See SI) ${ }^{84,85}$ and FIr6 ${ }^{40,53,54}$ (used in this study) are exclusively found as emitter in multi-layer PhOLEDs and not in SL-PhOLEDs using a single host (note that one example is reported but using a different host /co-host strategy ${ }^{47}$ ).

Thus, with Flrpic as sky blue emitter, SPA-3,6-F(POPh $\left.{ }_{2}\right)_{2}$ displays this time the lowest performance with a low EQE of $6.5 \%$ and a high $\mathrm{V}_{\text {on }}$ of $3.5 \mathrm{~V}$ in accordance with a bad charges recombination and injection. The EQE is interestingly increased to $8.6 \%$ with SPA-2-FPOPh ${ }_{2}$ and the $\mathrm{V}_{\text {on }}$ is decreased to $2.8 \mathrm{~V}$ signing a better charges injection, transport and recombination than in SPA-3,6-F(POPh $\mathbf{P}_{2}$. It is nevertheless difficult to assign why SPA-2-FPOPh ${ }_{2}$ displays a higher performance than SPA-3,6-F(POPh $\mathbf{P}_{\mathbf{2}}$ as the opposite was observed for the two other phosphors presented above. The case of SPA-2,7-F(POPh $\mathbf{P}_{2}$ is very different as it displays with Firpic excellent performances. Indeed, a very high EQE of $18.0 \%$ (CE $=39.0 \mathrm{~cd} / \mathrm{A}$ and $\mathrm{PE}=38.4 \mathrm{Im} / \mathrm{W}$ ) was measured at $0.04 \mathrm{~mA} / \mathrm{cm}^{2}$ (Table 3 ) and a maximum luminance of $8030 \mathrm{~cd} \cdot \mathrm{m}^{-2}$ at $80 \mathrm{~mA} / \mathrm{cm}^{2}$ was reached. We assign the very high efficiency of SPA-2,7-F $\left(\mathbf{P O P h}_{2}\right)_{2}$ to the combination of many parameters. The high and well balanced mobilities of charge carriers are surely involved in this high performance as it is a key point when designing a host material for SLPhOLED. It is also important to state that the LUMO levels of FIrpic and SPA-2,7-F(POPh $\left.{ }_{2}\right)_{\mathbf{2}}$ (Figure 6, Table 2 and 3) are very close and can also be involved in the present high performance. For these sky blue SL-PhOLEDs, the trend in term of $\mathrm{V}_{\text {on }}$ is similar to those exposed above for the other phosphors. Note that the $\mathrm{V}_{\text {on }}$ of SPA-2,7-F(POPh $\mathbf{2}_{\mathbf{2}}$ based device is very low, $2.5 \mathrm{~V}$, signing an efficient charge injection in the EML and a good hole and electron balance. In a similar device configuration and as far as we are aware, only one host previously reported in literature displays a higher performance with FIrpic as emitter (EQE of 20.3\%). ${ }^{36}$ This molecule, reported by Liu and coworkers, incorporates an 
electron poor bis(diphenylphosphineoxide)-fluorene unit and a pendant diphenyl amine ${ }_{\square 0 \mid}^{86}$ posselssingcle Online therefore a similar molecular structure than that described herein. The higher performance obtained with this host compared to that of SPA-2,7-F(POPh $)_{2}$ can be assigned to a better hole and electron mobilities balance. One can nevertheless note that our Flrpic-based devices display lower $\mathrm{V}_{\text {on }}$ ( $2.5 \mathrm{vs} 3$ $\mathrm{V})$, translating the electrochemical gap difference between the two molecules ( $2.79 \mathrm{vs} 2.86 \mathrm{eV}$ ).

Finally, in order to go deeper in the versatility of the present hosts and to reach devices emitting at shorter wavelength, blue phosphor FIr6 (HOMO $=-5.66 \mathrm{eV} / \mathrm{LUMO}=-2.32 \mathrm{eV}, \mathrm{E}_{\mathrm{T}}=2.70 \mathrm{eV}$ dispersed in the present hosts) was successfully used as emitter in identical SL-PhOLEDs. We were first surprised to note that SPA-2-FPOPh ${ }_{2}$ displays this time the highest efficiency in the series with an interesting maximal EQE of $9.1 \%$. This value is even higher than that recorded with FIrpic. Note that the LUMO level of SPA-2-FPOPh ${ }_{2}$ is very close to that of FIr6 $(-2.23 \mathrm{vs}-2.32 \mathrm{eV})$ and can be the explanation for this performance (the same observation, i.e. very close LUMO levels between host and guest, was also done with SPA-2,7-F(POPh $\left.{ }_{2}\right)_{2}$ and FIrpic above). Surprisingly, the EQE of SPA-2,7-F(POPh $\mathbf{2}_{\mathbf{2}}$ is very low, $6.5 \%$, whereas this host was the most efficient for all the other guests. We can tentatively assigned this feature to its relatively low $E_{T}, 2.76 \mathrm{eV}$, which is very close to that of FIr6 and back energy transfer may occur decreasing the PhOLED performance. Finally, as observed for FIrpic, the efficiency of SPA3,6-F(POPh $\left.{ }_{2}\right)_{2}$ is very low. The EQE reaches indeed $6.5 \%$ at a low current density but strongly decreases as the current density increases, showing the very bad performance of this host with this guest emitter. Compared to the only example of SL-PhOLED using FIr6 found literature (which is nevertheless different as a host/co-host is used in the EML), SPA-2-FPOPh $\mathbf{P}_{\mathbf{2}}$ displays significantly improved performance ( 9.1 vs $6.5 \%$ ), clearly highlighting the efficiency of the chemical design strategy used herein. ${ }^{47}$ To conclude, these data show the real difficulty to design versatile hosts, which can be efficiently used with RGB phosphors. As the thickness of the EML has not been optimized for this last phosphor, it is obvious that the encouraging performance observed with $\mathbf{S P A - 2 - F P O P h}$ will be easily overpassed in the future.

Table 3. Best SL-PhOLEDs performance using SPA-2,7-F(POPh $\left.{ }_{2}\right)_{2}, \mathbf{S P A - 3 , 6 - F}\left(\mathbf{P O P h}_{\mathbf{2}}\right)_{2}$ and SPA-2-FPOPh $\mathbf{~}_{\mathbf{2}}$ as host material. Device structure: ITO/PEDOT:PSS $(40 \mathrm{~nm}) /$ host + dopant $(100 \mathrm{~nm}) / \mathrm{LiF}(1.2 \mathrm{~nm}) / \mathrm{Al}$ $(100 \mathrm{~nm}) . \%$ of the phosphor used: $10 \%$ in mass. 


\begin{tabular}{|c|c|c|c|c|c|c|c|c|c|c|}
\hline & $V_{\text {on }}(\mathrm{V})$ & $\begin{array}{l}\text { EQE } \\
(\%)\end{array}$ & $\begin{array}{c}C E \\
(c d / A)\end{array}$ & $\begin{array}{c}\mathrm{PE} \\
(\operatorname{Im} / \mathrm{W})\end{array}$ & $\begin{array}{c}\mathrm{L} \\
\left(\mathrm{cd} / \mathrm{m}^{2}\right)\end{array}$ & $\begin{array}{l}\text { EQE } \\
(\%)\end{array}$ & $\begin{array}{c}C E \\
(c d / A)\end{array}$ & $\begin{array}{c}\mathrm{PE} \\
(\mathrm{Im} / \mathrm{W})\end{array}$ & $\begin{array}{c}\mathrm{L} \\
\left(\mathrm{cd} / \mathrm{m}^{2}\right)\end{array}$ & $\begin{array}{c}\text { Dol: } 10.10 \text { fols/DOT } \\
\text { coordinates } \\
(x ; y)\end{array}$ \\
\hline & & \multicolumn{4}{|c|}{$\begin{array}{c}\text { At } \\
10 \mathrm{~mA} / \mathrm{cm}^{2}\end{array}$} & \multicolumn{4}{|c|}{$\begin{array}{c}\text { Max } \\
\left(\text { at J }\left(\mathrm{mA} / \mathrm{cm}^{2}\right)\right)\end{array}$} & $\begin{array}{c}\mathrm{At} \\
10 \mathrm{~mA} / \mathrm{cm}^{2}\end{array}$ \\
\hline \multicolumn{11}{|c|}{ Red PhOLEDs $\left(10 \% \operatorname{Ir}(\mathrm{MDQ})_{2}(\mathrm{acac})\right)$} \\
\hline $\begin{array}{l}\text { SPA-2,7- } \\
F\left(P^{\prime} \mathrm{Ph}_{2}\right)_{2}\end{array}$ & 2.8 & 6.0 & 6.2 & 2.0 & 1501 & $\begin{array}{c}8.7 \\
(0.03)\end{array}$ & $\begin{array}{c}9.1 \\
(0.03)\end{array}$ & $\begin{array}{c}7.0 \\
(0.03)\end{array}$ & $\begin{array}{l}6843 \\
(170)\end{array}$ & $0.64 ; 0.36$ \\
\hline $\begin{array}{l}\text { SPA-3,6- } \\
\text { F(POPh }\end{array}$ & 3.6 & 4.4 & 4.4 & 1.3 & 1007 & $\begin{array}{c}5.3 \\
(0.04)\end{array}$ & $\begin{array}{c}5.4 \\
(0.04)\end{array}$ & $\begin{array}{c}3.0 \\
(0.04)\end{array}$ & $\begin{array}{l}2973 \\
(120)\end{array}$ & $0.64 ; 0.36$ \\
\hline $\begin{array}{l}\text { SPA-2- } \\
\text { FPOPh }_{2}\end{array}$ & 3.2 & 2.6 & 3.2 & 1.1 & 673 & $\begin{array}{c}4.5 \\
(0.04) \\
\end{array}$ & $\begin{array}{c}5.5 \\
(0.04) \\
\end{array}$ & $\begin{array}{c}3.5 \\
(0.04) \\
\end{array}$ & $151(220)$ & $0.63 ; 0.37$ \\
\hline \multicolumn{11}{|c|}{ Green PhOLEDs $\left(10 \% \operatorname{Ir}(\mathrm{ppy})_{3}\right)$} \\
\hline $\begin{array}{l}\text { SPA-2,7- } \\
F\left(P^{\prime} \text { Ph }_{2}\right)_{2} \\
\end{array}$ & 2.3 & 11.0 & 37.8 & 18.2 & 9946 & $\begin{array}{c}16.4 \\
(0.04)\end{array}$ & $\begin{array}{c}56.3 \\
(0.04)\end{array}$ & $\begin{array}{c}53.6 \\
(0.04)\end{array}$ & $\begin{array}{l}38970 \\
(180)\end{array}$ & $0.31 ; 0.63$ \\
\hline $\begin{array}{l}\text { SPA-3,6- } \\
\mathrm{F}\left(\mathrm{POPh}_{2}\right)_{2}\end{array}$ & 2.7 & 9.4 & 35.3 & 13.8 & 8099 & $\begin{array}{c}13.9 \\
(0.03)\end{array}$ & $\begin{array}{c}52.0 \\
(0.03)\end{array}$ & $\begin{array}{c}38.9 \\
(0.03)\end{array}$ & $\begin{array}{l}18610 \\
(150)\end{array}$ & $0.31 ; 0.63$ \\
\hline $\begin{array}{l}\text { SPA-2- } \\
\text { FPOPh }_{2}\end{array}$ & 2.7 & 7.5 & 25.6 & 13.4 & 6386 & $\begin{array}{c}10.4 \\
(0.02)\end{array}$ & $\begin{array}{c}35.6 \\
(0.02)\end{array}$ & $\begin{array}{c}32.9 \\
(0.02)\end{array}$ & $\begin{array}{c}15490 \\
(90)\end{array}$ & $0.31 ; 0.63$ \\
\hline \multicolumn{11}{|c|}{ Sky Blue PhOLEDs (10\% Flrpic) } \\
\hline $\begin{array}{l}\text { SPA-2,7- } \\
\left.\text { F(POPh })_{2}\right)_{2}\end{array}$ & 2.5 & 12.5 & 27.3 & 14.5 & 5276 & $\begin{array}{c}18.0 \\
(0.04)\end{array}$ & $\begin{array}{c}39.0 \\
(0.04)\end{array}$ & $\begin{array}{c}38.4 \\
(0.04)\end{array}$ & $8030(80)$ & $0.15 ; 0.37$ \\
\hline $\begin{array}{l}\text { SPA-3,6- } \\
\mathrm{F}\left(\mathrm{POPh}_{2}\right)_{2}\end{array}$ & 3.5 & 6.5 & 12.3 & 4.0 & 2013 & $\begin{array}{c}6.5 \\
(6.8)\end{array}$ & $\begin{array}{l}12.3 \\
(6.8)\end{array}$ & $\begin{array}{c}4.2 \\
(6.8)\end{array}$ & $2540(50)$ & $0.16 ; 0.38$ \\
\hline $\begin{array}{l}\mathrm{SPA-2} \\
\mathrm{FPOPh}_{2}\end{array}$ & 2.8 & 8.0 & 16.2 & 6.3 & 3896 & $\begin{array}{c}8.6 \\
(0.24) \\
\end{array}$ & $\begin{array}{c}17.3 \\
(0.24)\end{array}$ & $\begin{array}{c}10.5 \\
(0.24) \\
\end{array}$ & $\begin{array}{l}9578 \\
(100) \\
\end{array}$ & $0.15 ; 0.37$ \\
\hline \multicolumn{11}{|c|}{ Blue PhOLEDs (10\% Flr6) } \\
\hline $\begin{array}{l}\text { SPA-2,7- } \\
F\left(P^{\prime} O \mathrm{Ph}_{2}\right)_{2}\end{array}$ & 2.8 & 5.4 & 8.6 & 4.3 & 2220 & $\begin{array}{c}6.5 \\
(27.7) \\
\end{array}$ & $\begin{array}{c}10.4 \\
(27.7)\end{array}$ & $\begin{array}{c}4.5 \\
(27.7) \\
\end{array}$ & $2687(50)$ & $0.16 ; 0.33$ \\
\hline $\begin{array}{l}\text { SPA-3,6- } \\
\mathrm{F}\left(\mathrm{POPh}_{2}\right)_{2}\end{array}$ & 4.6 & 5.1 & 11.5 & 4.2 & 604 & $\begin{array}{c}6.5 \\
(1.2)\end{array}$ & $\begin{array}{l}14.7 \\
(1.2)\end{array}$ & $\begin{array}{c}6.8 \\
(1.2)\end{array}$ & $661(40)$ & $0.16 ; 0.32$ \\
\hline $\begin{array}{l}\text { SPA-2- } \\
\text { FPOPh }_{2}\end{array}$ & 2.9 & 9.0 & 15.9 & 7.9 & 3518 & $\begin{array}{c}9.1 \\
(14.6)\end{array}$ & $\begin{array}{c}16.2 \\
(14.6)\end{array}$ & $\begin{array}{c}7.7 \\
(14.6)\end{array}$ & $4952(60)$ & $0.15 ; 0.30$ \\
\hline
\end{tabular}

It should be finally mentioned that all the devices exhibited identical red, green or blue emission arising exclusively from their corresponding iridium complex (and are therefore independent of the matrix used), showing an efficient energy transfer cascade (see electroluminescent spectra for all the device in Figure 7). This is confirmed by the study of the emission spectra of the EML (host + guest $10 \%$ without electrodes), which are identical to the corresponding electroluminescent spectra (See SI). The CIE chromatic coordinates of the electroluminescent spectra are reported in Table 3 . It is particularly important to note that FIrpic based devices display CIE Coordinates of $(0.15,0.37)$ whereas those of FIr6 are shifted to $(0.15,0.30)$ confirming a more blue emission for the latter. 
A.
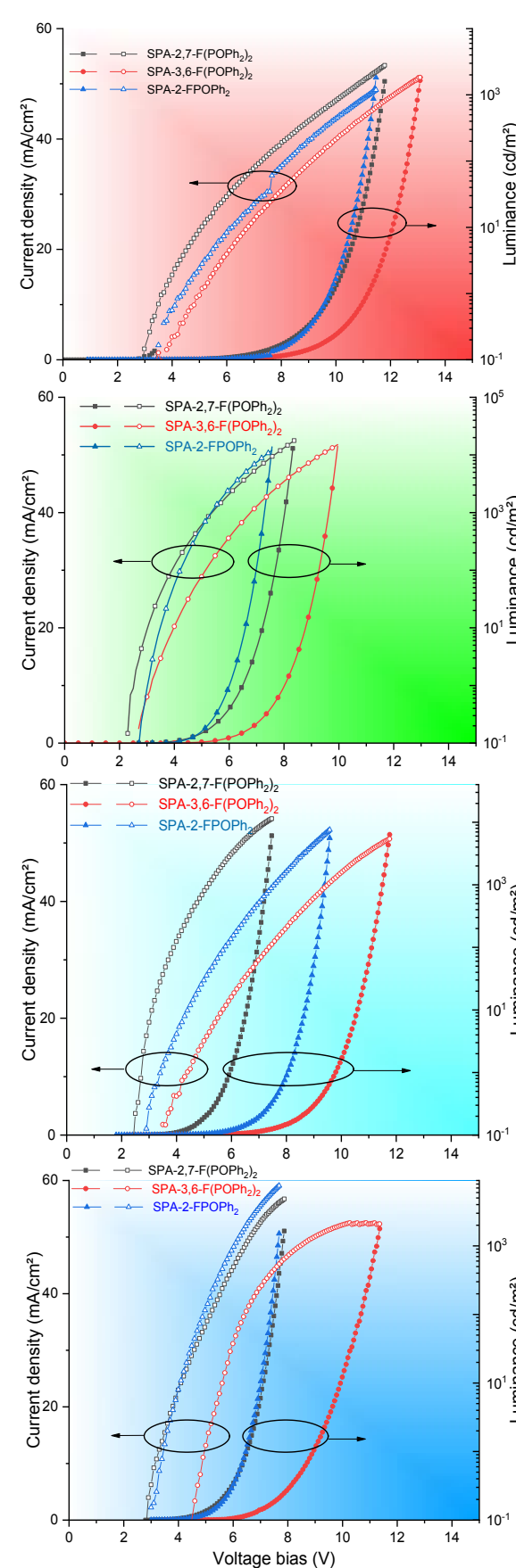

B.
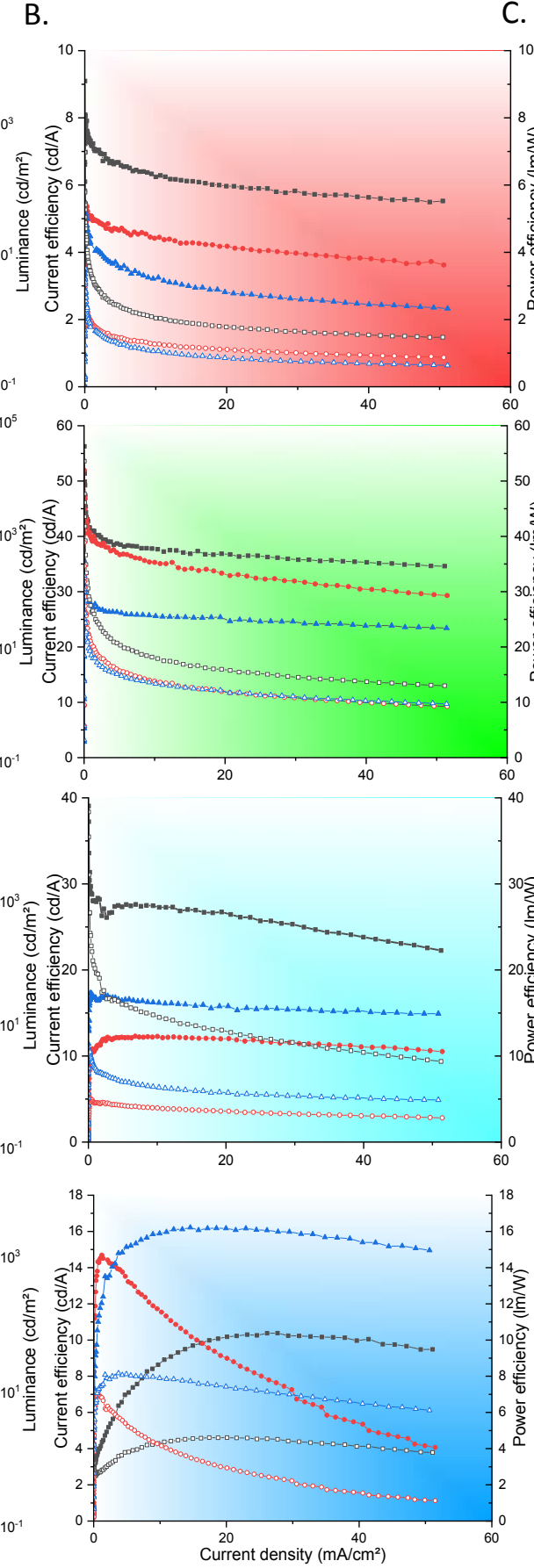

C.
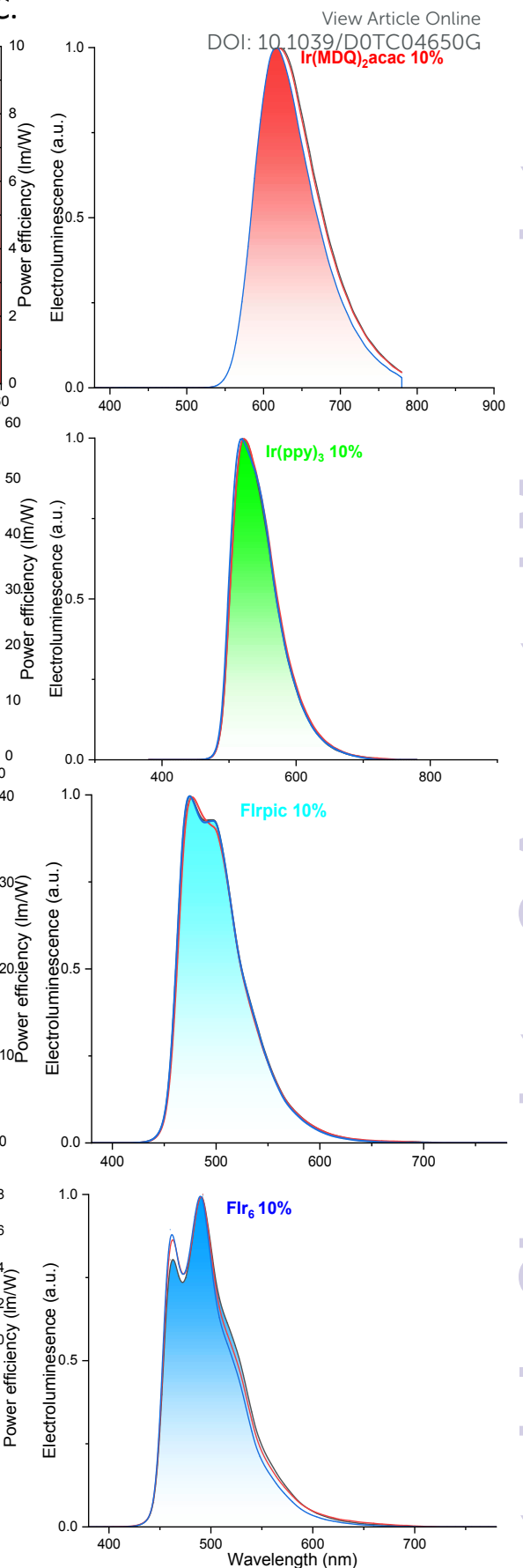

Figure 7. SL-PhOLEDs characteristics using as a host either SPA-2,7-F(POPh $)_{2}$ (black lines), SPA-3,6$\mathbf{F}(\mathbf{P O P h})_{2}$ (red lines) or SPA-2-FPOPh ${ }_{2}$ (blue lines). A) Current density $\left(\mathrm{mA} / \mathrm{cm}^{2}\right)$ and luminance $\left(\mathrm{cd} / \mathrm{m}^{2}\right)$ as a function of the bias voltage; B) Current efficiency (cd/A, filled symbols) and power efficiency $\left(\mathrm{Im} / \mathrm{W}\right.$, empty symbol) as a function of the current density $\left(\mathrm{mA} / \mathrm{cm}^{2}\right)$ and $\left.\mathrm{C}\right)$ Normalized EL spectra.

\section{Conclusion}

In this work, we have investigated different phenylacridine/diphenylphosphineoxide associations within a single host for RGB SL-PhOLEDs. The synthetic strategy developed is short, versatile, efficient, and uses cheap starting materials. For the future of the OLED technology, reducing the synthetic chemistry steps is highly required to reduce its environmental footprint. This work shows how the number and the position of the diphenylphosphine oxide units attached to the spirophenylacridinefluorene backbone significantly impact the physical and electronic properties. 
The three molecules investigated herein have been incorporated as host material in simplified sifiglesticle Online layer PhOLEDs with four different iridium complexes emitting in the red, green and blue region. With these conditions, we have shown how each parameter of the host (HOMO/LUMO energy levels, $E_{T}$, charge carriers mobility) influences the emission efficiency of the guest phosphor within the device and how a subtle combination of these three parameters is required. In addition, this work also reports the first examples of SL-PhOLEDs using the blue emitter FIr6. With this phosphor, the mono-

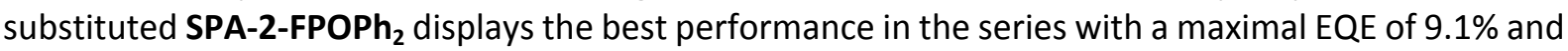
a low $\mathrm{V}_{\text {on }}$ below $3 \mathrm{~V}$. These first results appear very promising and deserve device optimizations in the future. As simplifying the device structure can be a central feature in the future of OLEDs, designing efficient and stable semi-conductors for this purpose is an important step. However, more researches are undoubtedly needed not only in term of molecular design but also in term of device engineering. Recently, it has been shown that specific treatment of ITO (using chlorinated ITO followed by UV ozone treatment as anode) is an efficient technique to improve the performance of SL-PHOLEDs. ${ }^{32}$ Combining the best devices architectures with the best host materials may result to very high efficiency SLPhOLEDs.

\section{Supporting Information}

Details on the materials synthesis, their structural, thermal and electrochemical properties, theoretical modeling, device data are provided in the supporting Information. 2D NMR studies and copies of NMR spectra are also included. The Supporting Information is available free of charge on the Publications website.

\section{Acknowledgments}

The authors would like to thank the ANR (SPIROQUEST, $\left.n^{\circ} 19-C E 05-0024\right)$ for financial support of this project and the Région Bretagne (DIADEM project) for PhD grant (FL). We would like to thank Dr Franck Camerel for his help in DSC measurements and the CRMPO (Rennes) for mass analysis. This work was granted access to the HPC resources of CINES under the allocation 2020-A0080805032 made by GENCI. The authors thank Dr J. F. Bergamini (Rennes) for the TOC material.

Received: ((will be filled in by the editorial staff)) Published online: ((will be filled in by the editorial staff)).

\section{Reference}

1. M. A. Baldo, D. F. O'Brien, Y. You, A. Shoustikov, S. Sibley, M. E. Thompson and S. R. Forrest, Nature, 1998, 395, $151-154$.

Y. Tao, C. Yang and J. Qin, Chem. Soc. Rev., 2011, 40, 2943-2970.

K. S. Yook and J. Y. Lee, Adv. Mater., 2014, 26, 4218-4233.

C. Poriel and J. Rault-Berthelot, J. Mater. Chem. C, 2017, 5, 3869-3897

Q. Wang, F. Lucas, C. Quinton, Y.-K. Qu, J. Rault-Berthelot, O. Jeannin, S.-Y. Yang, F.-C. Kong, S. Kumar, L.-S. Liao, C. Poriel and Z.-

Q. Jiang, Chem. Sci., 2020, 11, 4887-4894.

A. Maheshwaran, V. G. Sree, H.-Y. Park, H. Kim, S. H. Han, J. Y. Lee and S.-H. Jin, Adv. Funct. Mater., 2018, $28,1802945$.

W. Li, J. Li, D. Liu and Q. Jin, ACS Appl. Mater. Interfaces., 2016, 8, 22382-22391.

J.-J. Huang, Y.-H. Hung, P.-L. Ting, Y.-N. Tsai, H.-J. Gao, T.-L. Chiu, J.-H. Lee, C.-L. Chen, P.-T. Chou and M.-k. Leung, Org. Lett., 2016, 18, 672-675.

L. Ding, S.-C. Dong, Z.-Q. Jiang, H. Chen and L. S. Liao, Adv. Funct. Mater., 2015, 25, 645-650.

L.-S. Cui, Y.-M. Xie, Y.-K. Wang, C. Zhong, Y.-L. Deng, X.-Y. Liu, Z.-Q. Jiang and L.-S. Liao, Adv. Mater., 2015, $27,4213-4217$.

K. Udagawa, H. Sasabe, C. Cai and J. Kido, Adv. Mater., 2014, 26, 5062-5066.

Y. Im, S. Y. Byun, J. H. Kim, D. R. Lee, C. S. Oh, K. S. Yook and J. Y. Lee, Adv. Funct. Mater., 2017, 27, 1603007.

C. W. Lee and J. Y. Lee, Adv. Mater., 2013, 25, 5450-5454.

X. Tang, X.-Y. Liu, Y. Yuan, Y.-J. Wang, H.-C. Li, Z.-Q. Jiang and L.-S. Liao, ACS Appl. Mater. Interfaces, 2018, 10, $29840-29847$.

M. Kim and J. Y. Lee, ACS Appl. Mater. Interfaces, 2014, 6, 14874-14880.

X.-Y. Liu, X. Tang, Y. Zhao, D. Zhao, J. Fan and L.-S. Liao, ACS Appl. Mater. Interfaces, 2018, 10, 1925-1932.

K.-H. Kim, S. Lee, C.-K. Moon, S.-Y. Kim, Y.-S. Park, J.-H. Lee, J. Woo Lee, J. Huh, Y. You and J.-J. Kim, Nat. Comm., $2014,5,4769$.

W.-C. Chen, Y. Yuan, Z.-L. Zhu, Z.-Q. Jiang, S.-J. Su, L.-S. Liao and C.-S. Lee, Chem. Sci., 2018, 9, 4062-4070.

C. Poriel and J. Rault - Berthelot, Adv. Funct. Mat., 2020, 30, 1910040.

W.-Y. Hung, T.-C. Tsai, S.-Y. Ku, L.-C. Chi and K.-T. Wong, Phys. Chem. Chem. Phys., 2008, 10, 5822-5825. 

X. Qiao, Y. Tao, Q. Wang, D. Ma, C. Yang, L. Wang, J. Qin and F. Wang, J. Appl. Phys., 2010, 108, 034508.
J. Ye, Z. Chen, K. Wang, F. An, Y. Yuan, W. Chen, Q. Yang, X. Zhang and C.-S. Lee, Chem. Eur. J., 2014, 20, 13762D1376̧9:1039/D0TC04650G C. Zang, X. Peng, H. Wang, Z. Yu, L. Zhang, W. Xie and H. Zhao, Org. Electron., 2017, 50, 106-114.

Z. Liu, M. G. Helander, Z. Wang and Z. Lu, Org. Electron., 2009, 10, 1146-1151.

Q. Jiang, Y. Xu, T. Yu, X. Qiu, R. Zhao, D. Zhao, N. Zheng, D. Hu, Z. Xie and Y. Ma, New. J. Chem., 2019, 43, 6721-6727.

C.-H. Chen, W.-S. Huang, M.-Y. Lai, W.-C. Tsao, J. T. Lin, Y.-H. Wu, T.-H. Ke, L.-Y. Chen and C.-C. Wu, Adv. Funct. Mat., 2009, 19, 2661-2670.

M.-Y. Lai, C.-H. Chen, W.-S. Huang, J. T. Lin, T.-H. Ke, L.-Y. Chen, M.-H. Tsai and C.-C. Wu, Angew. Chem. Int. Ed., 2008, 47, 581585.

J. P. J. Markham, S.-C. Lo, S. W. Magennis, P. L. Burn and I. D. W. Samuel, App. Phys. Lett., 2002, 80, 2645-2647.

W.-Y. Hung, T.-C. Wang, H.-C. Chiu, H.-F. Chen and K.-T. Wong, Phys. Chem. Chem. Phys., 2010, 12, 10685-10687.

B. Huang, W. Jiang, J. Tang, X. Ban, R. Zhu, H. Xu, W. Yang and Y. Sun, Dyes Pigm., 2014, 101, 9-14.

S. Thiery, D. Tondelier, B. Geffroy, E. Jacques, M. Robin, R. Métivier, O. Jeannin, J. Rault-Berthelot and C. Poriel, Org. Lett., 2015, 17, 4682-4685.

Z. Wu, Z. Yang, K. Xue, C. Fei, F. Wang, M. Yan, H. Zhang, D. Ma and W. Huang, RSC Adv., 2018, 8, 11255-11261.

F. Lucas, O. A. Ibraikulov, C. Quinton, L. Sicard, T. Heiser, D. Tondelier, B. Geffroy, N. Leclerc, J. Rault-Berthelot and C. Poriel, Adv. Opt. Mater., 2020, 8, 1901225.

A. Yoshii, Y. Onaka, K. Ikemoto, T. Izumi, S. Sato, H. Kita, H. Taka and H. Isobe, Chem. Asian J., 2020, 15, $2181-2186$.

H.-H. Chang, W.-S. Tsai, C.-P. Chang, N.-P. Chen, K.-T. Wong, W.-Y. Hung and S.-W. Chen, Org. Electron., $2011,12,2025-2032$.

F.-M. Hsu, L.-J. Chien, K.-T. Chen, Y.-Z. Li and S.-W. Liu, Org. Electron., 2014, 15, 3327-3332.

Y. Yin, X. Wen, J. Yu, L. Zhang and W. Xie, IEEE Photonics Technology Letters, 2013, 25, 1041-1135.

Y. Yin, X. Piao, Y. Wang, J. Liu, K. Xu and W. Xie, App. Phys. Lett., 2012, 101, 063306.

K. S. Yook and J. Y. Lee, Adv. Mater., 2012, 24, 3169-3190.

K. Gao, K. Liu, X.-L. Li, X. Cai, D. Chen, Z. Xu, Z. He, B. Li, Z. Qiao, D. Chen, Y. Cao and S.-J. Su, J. Mater. Chem. C, 2017, 5, 1040610416.

C.-C. Lai, M.-J. Huang, H.-H. Chou, C.-Y. Liao, P. Rajamalli and C.-H. Cheng, Adv. Funct. Mat., 2015, 25, 5548-5556.

X.-D. Zhu, Y.-L. Zhang, Y. Yuan, Q. Zheng, Y.-J. Yu, Y. Li, Z.-Q. Jiang and L.-S. Liao, J. Mater. Chem. C, 2019, 7, 6714-6720.

Y. Zhao, C. Wu, P. Qiu, X. Li, Q. Wang, J. Chen and D. Ma, ACS Appl. Mater. Interfaces, 2016, 8, 2635-2643.

W. Song, L. Shi, L. Gao, P. Hu, H. Mu, Z. Xia, J. Huang and J. Su, ACS Appl. Mater. Interfaces, 2018, 10, 5714-5722.

Y. Miao, K. Wang, L. Gao, B. Zhao, H. Wang, F. Zhu, B. Xu and D. Ma, J. Mater. Chem. C, 2018, 6, 8122-8134.

W. Jiang, L. Duan, D. Zhang, G. Dong, L. Wang and Y. Qiu, J. Mater. Chem., 2010, 20, 6131-6137.

C. Fan, Y. Li, C. Yang, H. Wu, J. Qin and Y. Cao, Chem. Mater., 2012, 24, 4581-4587.

K. H. Yeoh, N. A. Talik, T. J. Whitcher, C. Y. B. Ng and K. L. Woon, Journal of Physics D: Applied Physics, $2014,47,205103$.

S. E. Jang and J. Y. Lee, J. Lumin., 2011, 131, 2788-2791.

N. C. Erickson and R. J. Holmes, App. Phys. Lett., 2010, 97, 083308.

J. Y. Xue, T. Izumi, A. Yoshii, K. Ikemoto, T. Koretsune, R. Akashi, R. Arita, H. Taka, H. Kita, S. Sato and H. Isobe, Chem. Sci., 2016, 7, 896-904.

K. Ikemoto, A. Yoshii, T. Izumi, H. Taka, H. Kita, J. Y. Xue, R. Kobayashi, S. Sato and H. Isobe, J. Org. Chem., 2016, 81, 662-666.

C. Wu, B. Wang, Y. Wang, J. Hu, J. Jiang, D. Ma and Q. Wang, J. Mater. Chem. C, 2019, 7, 558-566.

H.-H. Chou and C.-H. Cheng, Adv. Mater., 2010, 22, 2468-2471.

C. Poriel, L. Sicard and J. Rault-Berthelot, Chem. Comm., 2019, 55, 14238-14254.

C. Poriel and J. Rault - Berthelot, Acc. Chem. Res., 2018, 51, 1818-1830.

J.-D. Peltier, B. Heinrich, B. Donnio, E. Jacques, J. Rault-Berthelot and C. Poriel, ACS Appl. Mater. Interfaces, $2017,9,8219-8232$.

J.-D. Peltier, B. Heinrich, B. Donnio, O. Jeannin, J. Rault-Berthelot and C. Poriel, Chem. Eur. J., 2017, 23, 17290-17303.

S. Bebiche, P. Cisneros-Perez, T. Mohammed-Brahim, M. Harnois, J. Rault - Berthelot, C. Poriel and E. Jacques, Mater. Chem. Front., 2018, 2, 1631-1641.

L. Sicard, C. Quinton, J.-D. Peltier, D. Tondelier, B. Geffroy, U. Biapo, R. Métivier, O. Jeannin, J. Rault-Berthelot and C. Poriel, Chem. Eur. J., 2017, 23, 7719-7723.

S. Thiery, C. Declairieux, D. Tondelier, G. Seo, B. Geffroy, O. Jeannin, R. Métivier, J. Rault-Berthelot and C. Poriel, Tetrahedron, 2014, 70, 6337-6351.

C. Quinton, L. Sicard, O. Jeannin, N. Vanthuyne and C. Poriel, Adv. Funct. Mat., 2018, 28, 180340-180347.

M. Romain, D. Tondelier, B. Geffroy, O. Jeannin, E. Jacques, J. Rault-Berthelot and C. Poriel, Chem. Eur. J., 2015, 21, 9426-9439,. I. Bulut, P. Chavez, S. Fall, S. Mery, B. Heinrich, J. Rault-Berthelot, C. Poriel, P. Leveque and N. Leclerc, RSC Adv., 2016, 6, 2595225959.

M. Romain, D. Tondelier, O. Jeannin, B. Geffroy, J. Rault-Berthelot and C. Poriel, J. Mater. Chem. C, 2015, 3, 97010-97014.

M. Romain, M. Chevrier, S. Bebiche, T. Mohammed-Brahim, J. Rault-Berthelot, E. Jacques and C. Poriel, J. Mater. Chem. C, 2015, 3, 5742-5753.

M. Romain, D. Tondelier, B. Geffroy, A. Shirinskaya, O. Jeannin, J. Rault-Berthelot and C. Poriel, Chem. Commun., 2015, 51, 13131315. L. J. Sicard, H.-C. Li, Q.
2019, 58, 3848-3853. Interfaces., 2017, 9, 6194-6206.

C. Poriel, J. Rault-Berthelot, S. Thiery, C. Quinton, O. Jeannin, U. Biapo, B. Geffroy and D. Tondelier, Chem. Eur. J., 2016, 22, 17930-17935.

S. Thiery, D. Tondelier, C. Declairieux, B. Geffroy, O. Jeannin, R. Métivier, J. Rault-Berthelot and C. Poriel, J. Phys. Chem. C, 2015, 119, 5790-5805.

D. H. Ahn, S. W. Kim, H. Lee, I. J. Ko, D. Karthik, J. Y. Lee and J. H. Kwon, Nature Photonics, 2019, 13, 540-546. E. Baranoff and B. F. E. Curchod, Dalton Trans., 2015, 44, 8318-8329.

W.-H. Choi, G. Tan, W.-Y. Sit, C.-L. Ho, C. Y.-H. Chan, W. Xu, W.-Y. Wong and S.-K. So, Org. Electron., 2015, $24,7-11$.

J.-H. Seo, N.-S. Han, H.-S. Shim, J.-H. Kwon and J.-K. Song, Bull. Korean Chem. Soc., 2011, 32, 1415-1418. 

2013, 1, 808-821.

77. R. J. Holmes, B. W. D’Andrade, S. R. Forrest, X. Ren, J. Li and M. E. Thompson, App. Phys. Lett., 2003, 83, 3818-3820.

78. Y. L. Chang, Z. B. Wang, M. G. Helander, J. Qiu, D. P. Puzzo and Z. H. Lu, Org. Electron., 2012, 13, $925-931$.

$79 . \quad$ J. P. Duan, P. P. Sun and C. H. Cheng, Adv. Mater., 2003, 15, 224-228.

80. R. Mertens, The OLED Handbook: A Guide to OLED Technology, Industry \& Market, 2019 edition, 2019.

81. K. Klimes, Z.-Q. Zhu and J. Li, Adv. Funct. Mater., 2019, 29, 1903068.

82. S. Hu, J. Zeng, X. Zhu, J. Guo, S. Chen, Z. Zhao and B. Z. Tang, ACS Appl. Mater. Interfaces, 2019, 11, 27134-27144.

83. Y. Liu, L.-S. Cui, M.-F. Xu, X.-B. Shi, D.-Y. Zhou, Z.-K. Wang, Z.-Q. Jiang and L. S. Liao, J. Mater. Chem. C, 2014, 2, 2488-2495.

84. S. O. Jeon, S. E. Jang, H. S. Son and J. Y. Lee, Adv. Mater., 2011, 23, 1436-1441.

85. S. O. Jeon, K. S. Yook, C. W. Joo and J. Y. Lee, Adv. Funct. Mater., 2009, 19, 3644-3649.

86. F.-M. Hsu, C.-H. Chien, C.-F. Shu, C.-H. Lai, C.-C. Hsieh, K.-W. Wang and P.-T. Chou, Adv. Funct. Mater., $2009,19,2834-2843$. 


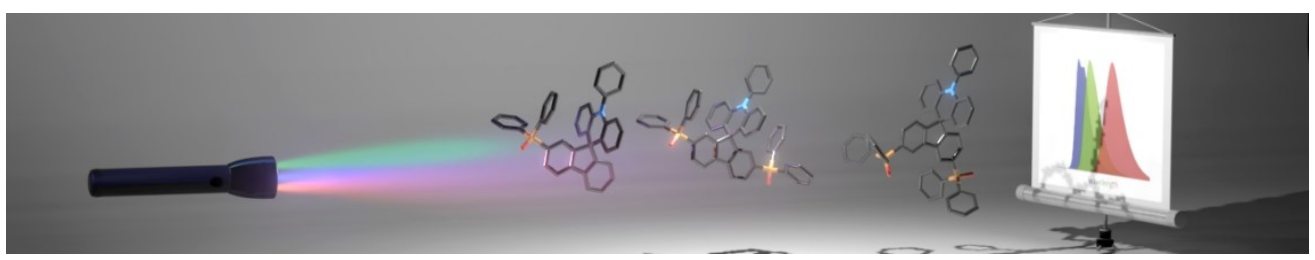

